\title{
Cellular cholesterol delivery, intracellular processing and utilization for biosynthesis of steroid hormones
}

\author{
Jie Hu+, Zhonghua Zhang ${ }^{+3}$, Wen-Jun Shen and Salman Azhar*1,2
}

\begin{abstract}
Steroid hormones regulate diverse physiological functions such as reproduction, blood salt balance, maintenance of secondary sexual characteristics, response to stress, neuronal function and various metabolic processes. They are synthesized from cholesterol mainly in the adrenal gland and gonads in response to tissue-specific tropic hormones. These steroidogenic tissues are unique in that they require cholesterol not only for membrane biogenesis, maintenance of membrane fluidity and cell signaling, but also as the starting material for the biosynthesis of steroid hormones. It is not surprising, then, that cells of steroidogenic tissues have evolved with multiple pathways to assure the constant supply of cholesterol needed to maintain optimum steroid synthesis. The cholesterol utilized for steroidogenesis is derived from a combination of sources: 1) de novo synthesis in the endoplasmic reticulum (ER); 2) the mobilization of cholesteryl esters (CEs) stored in lipid droplets through cholesteryl ester hydrolase; 3) plasma lipoprotein-derived CEs obtained by either LDL receptor-mediated endocytic and/or SR-BI-mediated selective uptake; and 4) in some cultured cell systems from plasma membrane-associated free cholesterol. Here, we focus on recent insights into the molecules and cellular processes that mediate the uptake of plasma lipoprotein-derived cholesterol, events connected with the intracellular cholesterol processing and the role of crucial proteins that mediate cholesterol transport to mitochondria for its utilization for steroid hormone production. In particular, we discuss the structure and function of SR-BI, the importance of the selective cholesterol transport pathway in providing cholesterol substrate for steroid biosynthesis and the role of two key proteins, StAR and PBR/TSO in facilitating cholesterol delivery to inner mitochondrial membrane sites, where P450scc (CYP11A) is localized and where the conversion of cholesterol to pregnenolone (the common steroid precursor) takes place.
\end{abstract}

\section{Introduction}

Cholesterol is a starting material for the biosynthesis of steroid hormones; these fat soluble, low molecular weight substances play diverse and important physiological functions (Table 1). There are five major classes of steroid hormones: testosterone (androgen), estradiol (estrogen), progesterone (progestin), cortisol/corticosterone (glucocorticoid), and aldosterone (mineralocorticoids). Testosterone and its more potent metabolite dihydrotestosterone (DHT), progesterone and estradiol are classified as sex-steroids, whereas cortisol/corticosterone and aldosterone are collectively referred to as cor-

\footnotetext{
* Correspondence: salman.azhar@va.gov

1 Geriatric Research, Education and Clinical Center, VA Palo Alto Health Care

System, Palo Alto, California 94304, USA

+ Contributed equally

Full list of author information is available at the end of the article
}

ticosteroids [1-3]. All these steroid hormones are synthesized from cholesterol through a common precursor steroid, pregnenolone [1-3], which is formed by the enzymatic cleavage of a 6-carbon side-chain of the 27carbon cholesterol molecule, a reaction catalyzed by the cytochrome P450 side-chain cleavage enzyme (P450scc, CYP11A1) (Fig. 1) [4-6]. The adrenal gland produces both corticosteroids and androgens (dihydroepiandosterone [DHEA], and androstenedione); aldosterone is mainly produced by the cells of the zona glomerulosa layer, cortisol/corticosterone is principally produced by the adrenocortical cells of the zona fasciculata layer and adrenal DHEA whereas androstenedione is synthesized by cells of the zona reticularis layer (Table 1) [1,7-9]. The ovarian granulosa cells mainly secrete progesterone (and its metabolite 20a-hydroxyprogesterone) and estradiol; 
Table 1: Major steroids and their physiological functions

\begin{tabular}{|c|c|c|c|}
\hline Steroidogenic Tissues & Trophic Hormone & Steroids(s) & Physiological Functions \\
\hline \multicolumn{4}{|l|}{ Ovary } \\
\hline Granulosa cells & FSH & Estradiol & $\begin{array}{l}\text { Estrogen, a principal female sex steroid, required for growth and } \\
\text { ovulation, responsible for secondary female sex characteristics, regulator } \\
\text { of cardiovascular physiology, bone integrity and neuronal growth }\end{array}$ \\
\hline $\begin{array}{l}\text { Luteinized Granulosa/ } \\
\text { luteal Cells }\end{array}$ & $\mathrm{LH}$ & Progesterone & $\begin{array}{l}\text { A progestin, required for follicular growth and ovulation, responsible for } \\
\text { changes associated with luteal phase of the menstrual cycle, essential for } \\
\text { the establishment and maintenance of early pregnancy }\end{array}$ \\
\hline Theca-interstitial Cells & $\mathrm{LH}$ & $\begin{array}{l}\text { Testosterone } \\
\text { Androstenedione }\end{array}$ & $\begin{array}{l}\text { Androgens, precursors for estrogens, transported into granulosa cells, } \\
\text { where they are converted into estardiol and other estrogens by } \\
\text { aromatase (CYP19A1) enzyme }\end{array}$ \\
\hline \multicolumn{4}{|l|}{ Testis } \\
\hline Leydig cells & $\mathrm{LH}$ & Testosterone & $\begin{array}{l}\text { The most prevalent male sex hormone (androgen); testosterone and its } \\
\text { biologically active form, dihydrotestosterone (DHT) are necessary for } \\
\text { normal spermatogenesis and development, responsible for secondary } \\
\text { sex characteristics, responsible for increased muscle mass, sexual } \\
\text { function, body hair and decreased risk of osteoporosis }\end{array}$ \\
\hline \multicolumn{4}{|l|}{ Adrenal gland } \\
\hline Z. glomerulosa Cells & $\begin{array}{l}\text { ACTH, } \mathrm{K}^{+} \\
\text {Angiotensin II }\end{array}$ & Aldosterone & $\begin{array}{l}\text { The principal mineralocorticoid, raises blood pressure and fluid volume, } \\
\text { enhances sodium reabsorption in the kidney, sweat gland, stomach and } \\
\text { salivary gland and also enhances excretion of potassium and hydrogen } \\
\text { ions from the kidney. }\end{array}$ \\
\hline Z. glomerulosa Cells & ACTH & Cortisol & $\begin{array}{l}\text { The dominant glucocorticoid in humans (in rodents, the major } \\
\text { glucocorticoid is corticosterone), elevates blood pressure and } \mathrm{Na}^{+} \\
\text {uptake, involved in stress adaptation, regulates carbohydrate, protein } \\
\text { and lipid metabolism nearly opposite to that of insulin, influences } \\
\text { inflammatory reactions and numerous effects on the immune system. }\end{array}$ \\
\hline Z. reticularis Cells & $\begin{array}{l}\text { ACTH POC-derived } \\
\text { peptide Other } \\
\text { factors }\end{array}$ & $\begin{array}{l}\text { Androstenedione } \\
\text { DHEA DHEA-sulfate }\end{array}$ & $\begin{array}{l}\text { The function of adrenal androgens is not well understood, except that } \\
\text { they contribute to the maintenance of secondary sex characteristics, may } \\
\text { also be involved in the regulation of bone mineral density, muscle mass } \\
\text { and may beneficial actions against type } 2 \text { diabetes and obesity }\end{array}$ \\
\hline Placenta & $\begin{array}{l}\text { Peptide growth } \\
\text { Factors, cAMP }\end{array}$ & $\begin{array}{l}\text { Progesterone } \\
\text { Estrogens }\end{array}$ & Maintenance of pregnancy \\
\hline \multicolumn{4}{|l|}{ Brain } \\
\hline $\begin{array}{l}\text { Neurons, Glial cells } \\
\text { Purkinje cells }\end{array}$ & $\begin{array}{l}\text { Neurotransmitters } \\
\text { Neuropeptides }\end{array}$ & $\begin{array}{l}\text { Progesterone } \\
\text { Estradiol, DHEA, } \\
\text { ALLO, THDOC }\end{array}$ & $\begin{array}{l}\text { Neurosteroids are implicated in various processes such as proliferation, } \\
\text { differentiation, activity and survival of nerve cells and a variety of } \\
\text { neuronal functions including control and behavior, neuroendocrine and } \\
\text { metabolic processes. }\end{array}$ \\
\hline
\end{tabular}

ovarian theca cells predominantly synthesize androgens, and ovarian luteal cells secrete progesterone (and its metabolite 20 $\alpha$-hydroxyprogesterone), while testicular Leydig cells are the site of testosterone production (Table 1) [1,7-9]. Progesterone is also synthesized by the corpus luteum during the first 6-8 weeks of gestation, but during pregnancy the main source of progesterone is the placenta $[10,11]$. The brain also synthesizes steroids de novo from cholesterol through mechanisms that are at least partly independent of peripheral steroidogenic cells [[1214] and references there in]. Such de novo synthesized brain steroids are commonly referred to as neurosteroids [12-14].
Although adrenal, ovarian and testicular steroidogenesis is primarily under the control of tissue-specific tropic hormones (discussed below); the availability of adequate cholesterol substrate is also a critical requirement for the optimal steroid hormone production. The steroidogenic tissues and cells have the potential to obtain cholesterol for steroid synthesis from at least four potential sources (Fig. 2): a) cholesterol synthesized de novo from acetate; b) cholesterol obtained from plasma low-density lipoprotein (LDL) and high-density lipoprotein (HDL); c) cholesterol-derived from the hydrolysis of stored cholesterol esters in the form of lipid droplets; and d) cholesterol interiorized from the plasma membrane. Although all three major steroidogenic organs (adrenal, testis and 


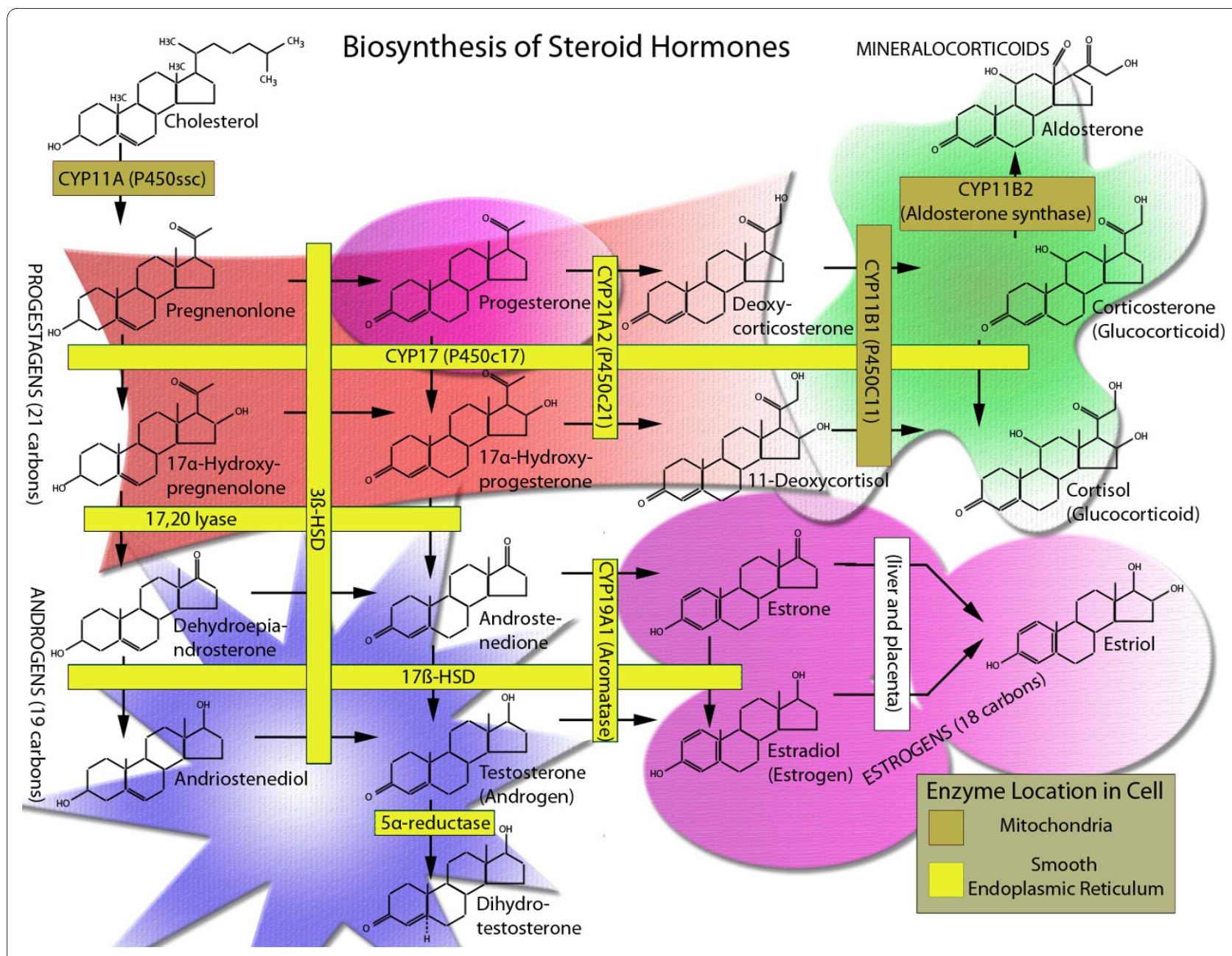

Figure 1 Principal steps involved in the biosynthesis of various steroid hormones. Modified from Payne and Hales and website [1,305]

ovary) can synthesize cholesterol de novo under the influence of the tropic hormone, the adrenal and ovary preferentially utilize cholesterol supplied from plasma LDL and HDL via the LDL-receptor mediated endocytic pathway and SR-BI-mediated selective pathway, respectively $[9,15-20]$. The use of LDL or HDL as the source of cholesterol for steroidogenesis appears to be species dependent; rodents preferentially utilize the SR-BI/selective pathway while humans, pigs and cattle primarily employ the LDL/LDL-receptor endocytic pathway to meet their cholesterol need for steroid synthesis. In contrast, testicular Leydig cells under normal physiological conditions rely heavily on the use of endogenously synthesized cholesterol for androgen (testosterone) biosynthesis $[9,20]$.

This review is focused on the role of cholesterol in the regulation of steroidogenesis. We first present an overview of various enzymatic pathways involved in the conversion of cholesterol to tissue-specific steroid hormones. Next, we summarize our current understanding about the molecules and processes that participate in the uptake of plasma lipoprotein-derived cholesterol with particular emphasis on the SR-BI/selective cholesterol transport pathway, events connected with the intracellular processing and trafficking of cholesterol and key proteins which facilitate the transport of cholesterol to and within the mitochondria for steroid synthesis.

\section{Biosynthesis of steroid hormones--an overview}

The overall rate of steroidogenesis (i.e., steroid hormone production) is controlled by tropic (peptide) hormones [21-26]. The type of steroid hormone that can be synthesized by a particular cell type is dictated by its complement of peptide hormone receptor, its response to peptide hormone stimulation and its genetically expressed complement of steroiodgenic enzymes (Fig. 1). Thus, adrenocorticotropic hormone (ACTH) stimulates cortisol/corticosterone in adrenocortical fasciculatareticularis cells, angiotensin II (AII) and potassium regulate aldosterone synthesis in adrenal glomerulosa cells, 


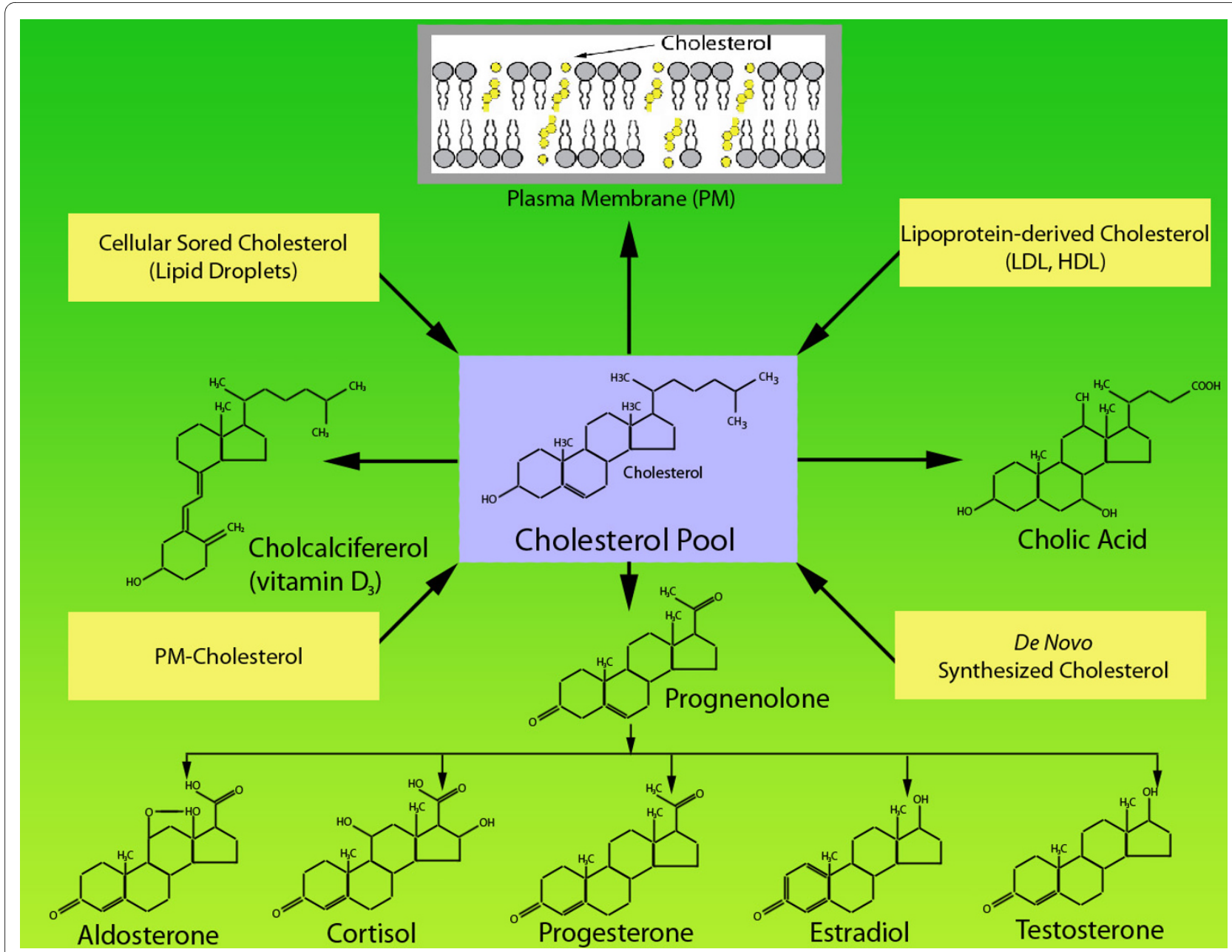

Figure 2 Potential sources of cholesterol for product formation (steroids, vitamin $\mathrm{D}$ and bile acids) and membrane biogenesis

follicle-stimulating hormone (FSH) controls the progesterone and estrogen synthesis in ovarian granulosa cells, whereas luteinizing hormone ( $\mathrm{LH})$ regulates progesterone synthesis in luteinized ovarian granulosa-luteal cells, androgen production in ovarian theca-interstitial cells and testosterone synthesis in testicular Leydig cells (Table 1) [27-38]. The adrenal gland is also responsible for the synthesis of adrenal androgens [39,40]. Tropic hormones (LH, FSH or ACTH) induce adrenocortical and gonadal steroidogenesis by binding to their respective $\mathrm{G}$ proteincoupled receptors, leading to activation of adenylate cyclase, which generates cAMP and activates cAMPdependent protein kinase (PKA) [21-25]. Stimulation of the cAMP-PKA signaling cascade exerts both acute and chronic effects on the regulation of steroid hormone production. The acute steroidogenic response, which occurs on the order of minutes, is characterized by a rapid mobilization of lipid droplet stored CEs and increased delivery of cholesterol to the mitochondrial cytochrome P450 cholesterol side-chain cleavage (P450scc) enzyme (encoded by CYP11A1) followed by rapid synthesis of new steroids. More chronic, long-term regulation of steroidogenesis also occurs at the level of the transcription of the genes for the steroidogenic enzymes to enhance, which results in the enhanced synthetic capacity of the cell [41-45]. Note: angiotensin (AII) stimulation of aldosterone biosynthesis in adrenal glomerulosa cells is primarily mediated by the protein kinase $\mathrm{C}$ signaling cascade, whereas potassium stimulation of aldosterone production also involves $\mathrm{Ca}^{2+}$-calmodulin-dependent kinase [26].

Although the final steroid product differs for these several cell types (described above), the first committed reaction in the biosynthetic pathway is the same, i.e., the conversion of cholesterol to pregnenolone by the cytochrome P450 cholesterol side-chain cleavage (P450scc) enzyme (CYP11A1). P450scc is an enzyme complex consisting of a flavoprotein (NADH-adrenodoxin reductase), a ferredox (adrenodoxin) and a cytochrome P450 localized on an inner mitochondrial membrane [3,7]. P450scc 
catalyzes three distinct reactions: $20 \alpha$-hydroxylation, 22 hydroxylation and scission of 20, 22 carbon-carbon bond, thus converting cholesterol to pregnenolone [3,7]. This initial step in steroid hormone (pregnenolone) synthesis also represents a rate limiting step. The rate limiting nature of this step does not result from a limitation of the P450scc activity itself (conversion of cholesterol to pregnenolone) but from limitation of access of cholesterol to the substrate site of P450scc, i.e., delivery of substrate cholesterol from an outer to an inner mitochondrial membrane where P450scc resides [46-50].

The pregnenolone produced in the rate-limiting step is further exposed to endoplasmic reticulum and mitochondria for further modifications $[1,2,7,51]$. It is first converted to progesterone by the enzyme $\Delta^{5}-3 \beta$ hydroxysteroid dehydrogenase isomerase (3ßHSD), which is also one of the main steroids produced by the steroidogenic cells of the ovary. In zona fasciculata cells of the adrenal cortex, progesterone is hydroxylated to $17 \alpha$-hydroxyprogesterone by P450c17 (CYP17), which is subsequently metabolized to 11-deoxycortisol (or deoxycorticosterone) by P450c21 (CYP21A2). The final step in cortisol biosynthesis takes place in the mitochondria and involves the conversion of 11-deoxcortisol (deoxycorticosterone) to cortisol or to corticosterone in rodents by the enzyme P450c11 (CYP11B1). The next two steps in aldosterone biosynthesis are catalyzed by aldosterone synthase (CYP11B2), which converts 11-deoxycorticosterone to corticosterone and subsequently to aldosterone. In testicular Leydig cells, pregnenolone is converted to testosterone via two pathways known as the $\Delta^{4}$ and $\Delta^{5}$ pathways. The relative activities of the two pathways are known to vary according to species [1]. The $\Delta^{4}$ involves sequential conversion of pregnenolone to progesterone to $17 \alpha$-hydroxyprogesterone to androstenedione to testosterone, while in the $\Delta^{5}$ pathway pregnenolone is converted to $17 \alpha$-hydroxypregnenolone to dehydroepiandrosterone to testosterone through either androstenediol or androstenedione. In the ovary, testosterone is further metabolized to estradiol, a reaction catalyzed by aromatase (CYP19A1). In addition, estradiol can also be formed through combined actions of aromatase (CYP19A1) and 17-hydroxysteroid dehydrogenase (17HSD1) (Fig. 1).

\section{De novo cholesterol synthesis}

Like many tissues, all steroid producing tissues and cells are capable of synthesizing cholesterol de novo [9,15$18,20]$. Biosynthesis of 27-carbon skeleton of cholesterol involves the conversion of acetate (acetyl CoA) through a series of complex enzymatic steps requiring the participation of numerous enzymes [52]. Among the major steps, mevalonate is formed by the condensation of 3 molecules of acetyl-CoA, a reaction catalyzed by the rate limiting enzyme HMG-CoA-reductase, which is converted to squalene, a 30-carbon linear structure followed by cyclization to yield lanosterol and subsequently removal of 3 carbons to produce cholesterol. The endoplasmic reticulum (ER)-associated integral membrane protein complex, SCAP/SREBP, transcriptionally controls the expression of the genes of many enzymes involved in cholesterol biosynthesis including the rate-limiting enzyme, HMG-CoA reductase [52,53]. In steroidogenic cells, the de novo cholesterol biosynthesis is also under the control of tropic hormone [15-18]. Indeed, adrenal, ovarian and testicular Leydig cell cholesterol biosynthesis as well as HMG-CoA reductase is rapidly stimulated upon exposure to tropic hormone [15-18]. Newly synthesized cholesterol primarily moves initially from the ER to the plasma membrane (PM) [54-57]. This energy dependent and predominantly nonvesicular trafficking process appears to require the participation of cholesterol-rich, sphingolipid-rich domains (i.e., lipid rafts/caveolae) and proteins such as caveolin, heat shock proteins and possibly other soluble sterol carrier candidate proteins such as OSBP, ORPs, SCP2, START domain containing proteins and phosphoinositides but not NCP1 [58-66]. After endogenously synthesized cholesterol is transported to the PM, its immediate fate is not well understood at present. While newly synthesized cholesterol is preferentially translocated to the PM, excess cellular cholesterol from other cellular organelles including PM is transported back to ER for esterification. The PM reverse cholesterol transport to ER is suggested to involve at least two pathways: a) a vesicular route via an endosome and/or Golgi; and b) a nonvesicular alternative route $[55,66]$. It should also be mentioned that retrograde transport of cellular cholesterol to ER and translocation of newly synthesized ER cholesterol to PM follow different itineraries $[55,66]$. Cholesterol esterification is primarily catalyzed by ERlocalized ACAT1 and newly formed CEs are stored along with triglycerides in the core of cytoplasmic lipid droplets [66-68]. Little is known about the mechanisms that control the biogenesis of lipid droplets, but it is clear that they are synthesized at and bud off from ER [69-71]. In steroidogenic cells of adrenal, ovary and testis, both the formation and depletion of lipid droplets is hormonally regulated. As noted before, the lipid droplet-associated cholesterol serves as a source of substrate for steroid hormone synthesis in response to acute hormonal stimulation [72-81].

\section{Receptor-mediated uptake and internalization of plasma lipoprotein-derived cholesterol} (a) LDL(B/E)-receptor-mediated endocytic uptake of LDLcholesterol

Although cellular de novo cholesterol synthesis and cholesteryl esters stored in lipid droplets can potentially sup- 
ply adequate amounts of cholesterol substrate to support steroidogenesis, the overwhelming evidence now suggests that the adrenal and ovary (and testicular Leydig cells under certain conditions) preferentially utilize plasma lipoprotein-derived cholesterol for steroid synthesis $[9,20]$. One pathway by which steroid producing cells acquire cholesterol is from plasma LDL, or other apolipoprotein B- (apoB) or apoE-containing lipoproteins via the LDL $(B / E)$ receptor-mediated endocytic pathway (Fig. 3) [19]. LDL or other relevant apoB/apoE lipoproteins bind to the LDL receptor initially localized at the plasma membrane (PM), which subsequently translocate to specialized regions of the plasma membrane, called the coated pits. The coated pits, made of clathrin protein, and some other accessory, invaginate, and pinch off from the PM in the form of coated vesicles $[19,66]$. These coated vesicles in the cell interior fuse with early endosomes, shed off their clathrin coat, and fuse with each other to form larger vesicles, called endosomes. At this stage, the LDL-receptor complex rapidly dissociates as the endosomal $\mathrm{pH}$ falls, and the released, but fully intact LDLreceptors are delivered to the endocytic recycling compartments (ERC) for their return itinerary to the PM [66]. The LDL cholesteryl esters (CEs) are hydrolyzed in a unique acid lipase-enriched compartment of early endosomes, the released cholesterol accumulates in the late endosomes/lysosomes, and subsequently through some unknown mechanisms is transported to PM as a membrane constituent, ER for esterification by the resident ER enzyme acyl-coenzyme A:cholesterol acyltransferase I (ACAT1) and storage in lipid droplets, or mitochondria for the synthesis of steroid hormones [67-71,82-85].

A pair of proteins called Nieman-Pick type $\mathrm{C} 1$ and $\mathrm{C} 2$ (NPC1 and NPC2, respectively) appear to be important in the movement of unesterified cholesterol out of the late endosomes and lysomes [66,86-89]. NPC1 is a polytopic, sterol-sensing protein of 1,278 amino acids located in the membranes of late endosomes and lysosomes that, along with NPC2, a cholesterol binding soluble protein of 131 amino acids located within lysosomes, facilitates the movement of cholesterol to various organelles by mechanisms not yet understood $[66,88,89]$. NPC1 appears to be important in trafficking LDL-cholesterol, particularly under conditions in which the substrate for steroidogenesis is primarily supported by LDL-cholesterol, but does not appear to be involved in other pathways for cholesterol delivery for steroidogenesis $[90,91]$. Additional proteins are also involved in this process such as MLN64 which facilitates the movement of lysosomal cholesterol to mitochondria for steroidogenesis [92,93]. MLN64 (StarD3) is a polytopic protein that is also found localized to late endosomes along with NPC1 and is a member of the StAR-related lipid transfer (START) domain superfamily that possesses cholesterol binding and transport activity [94]. However, targeted mutation of MLN64 in mice caused only minor alterations in sterol metabolism in vivo, but defects in cholesterol utilization for steroidogenesis were still seen in vitro, consistent with the existence of multiple mechanisms for cholesterol delivery for steroidogenesis. In addition, considerable evidence now indicates that transport of late endosomal/lysosomal LDL-cholesterol to other cellular destinations including mitochondria may also involve an endosomal-specific Rab 9 GTPase-dependent vesicular trafficking mechanism [66,95-97].

\section{(b) SR-BI-mediated 'selective' uptake of HDL-cholesterol (i) Molecular characteristics and the functional expression of SR-BI}

Whereas LDL-receptor-mediated uptake of cholesterol allows for its efficient delivery, steroidogenic cells can process exceptionally large quantities of lipoproteinderived cholesteryl esters through a specialized pathway known as the "selective" cholesteryl ester uptake pathway (Fig. 3) [98-100]. In fact, the "selective" cholesterol uptake pathway is quantitatively the most important source for cholesterol delivery for steroidogenesis in the tropic-hormone stimulated rodent adrenal and ovary [9,20,99-102]. The term "selective" cholesterol uptake is used when cell surface bound cholesterol-rich lipoproteins (HDL or LDL, regardless of lipoprotein composition) release cholesteryl esters without the parallel uptake and lysosomal degradation of the lipoprotein particle itself [72,73,98100,103]. Tropic hormone (ACTH or LH)-stimulated rodent adrenal and ovary (and under certain conditions testicular Leydig cells) rely heavily on selective cholesteryl ester uptake to fulfill their cholesterol needs for steroid synthesis $[9,20,72,73,99-102]$. The pathway is also functional in humans, in rodent liver and a variety of cultured cells such as isolated primary hepatocytes and hepatic cell lines, fibroblasts, adipocytes, and macrophages, although it may be quantitatively less important in humans [9,20].

Scavenger receptor class B, type I (SR-BI) is a physiologically relevant cell surface receptor responsible for "selective" uptake of lipoprotein-derived cholesteryl esters [104]. SR-BI is a member of the class B scavenger receptor family that also includes CD36, LIMPII, and SRBII (an isoform of SR-BI with an alternate C-terminal cytoplasmic tail) $[9,20,105]$. SR-BI, like the other family members, contains two transmembrane domains, two cytoplasmic domains (the amino- and carboxyl terminal domains), as well as a large extracellular domain (ECD) containing a cysteine-rich region and multiple sites for $\mathrm{N}$-linked glycosylation $[9,20,105]$. Cells, which have high levels of SR-BI, efficiently utilize the selective pathway in delivering cholesteryl esters for use in steroid hormones or product synthesis $[9,20]$. In rodents, SR-BI is abun- 


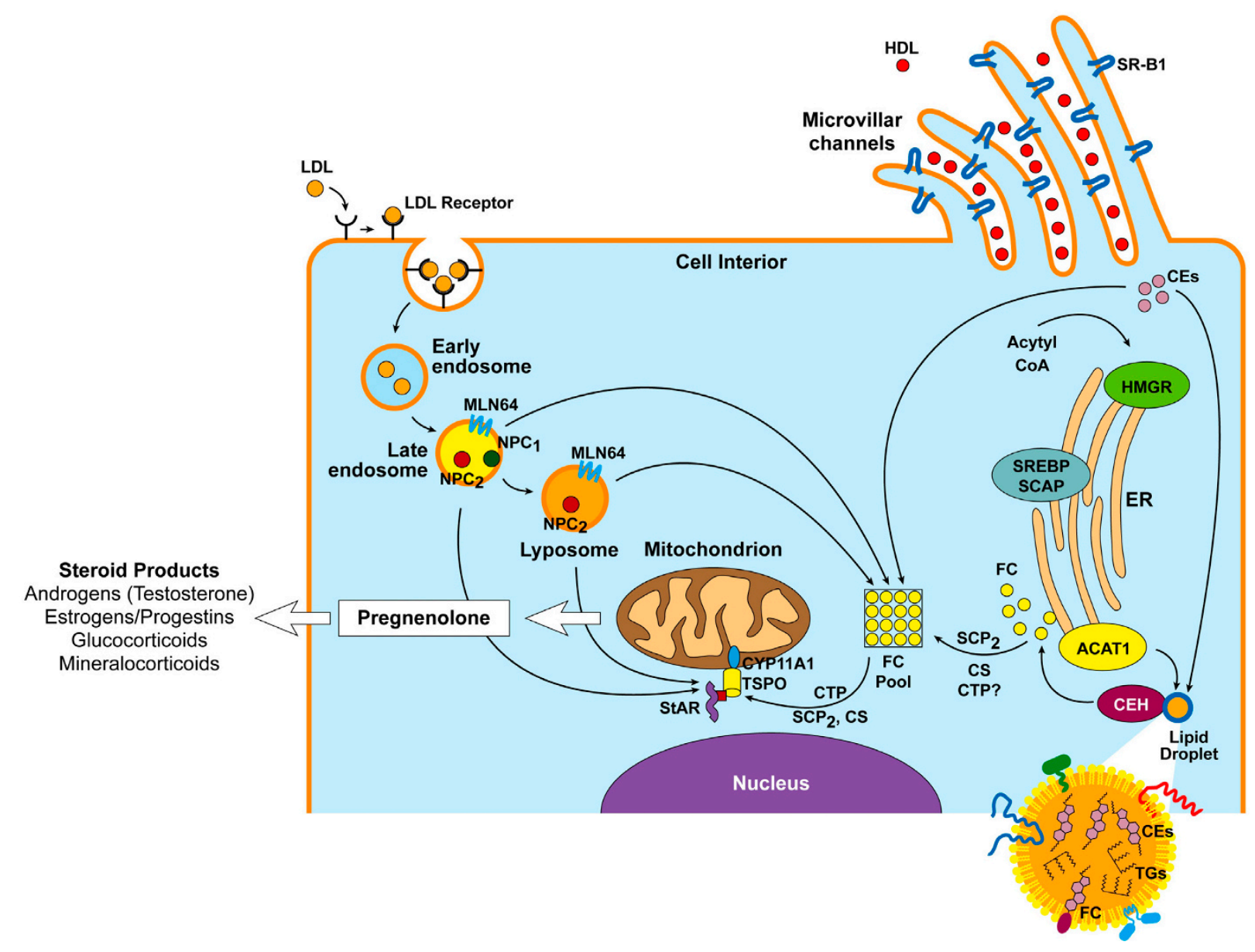

Figure 3 Diagrammatic representation of the molecular and cellular events involved in the selective and endocytic uptake and intracellular processing of the lipoprotein-derived cholesteryl esters for steroid hormone biosynthesis by adrenal and gonadal tissues. ACATA1, acylcoenzyme A:cholesterol acyltransferase I; CEs, cholesteryl esters; CS, cytoskeleton; CYP11A1, cytochrome P450 side-chain cleavage enzyme (P450scc); FC, free cholesterol; NPC1, Nieman-Pick type C1; NPC2, Nieman-Pick type C2; SCP2, sterol carrier protein2; SREBP, sterol-regulatory element-binding proteins; SCAP, SREBP cleavage-activating protein. StAR, steroidogenic acute regulatory protein; TGs, triglycerides; TSPO, translocator protein. Modified from Chang et al, Rone et al, and Farese and Walther [68,288,306].

dantly expressed in the liver, but also in steroidogenic cells of the adrenal gland, ovary, and testis where SR-BI levels are regulated by tropic hormones and influence the selective uptake of HDL-CE, and ultimately, steroidogenesis in these organs $[74,75,106-110]$.

It is also of interest that steroiodogenic tissues, which express high levels of SR-BI in vivo, are endowed with an intricate microvillar system for the trapping of lipoproteins $[111,112]$. This general region of steroidogenic cells is referred to as the microvillar compartment, and the specialized space created between adjacent microvilli are called microvillar channels; these are specialized domains that form by staking of microvilli or the juxtaposition of microvilli with the plasma membrane. It is the microvillar channels where the various lipoproteins are trapped prior to the selective uptake of CEs into cells [111-113]. Electron microscopic immunocytochemical techniques reveal heavy labeling for SR-BI specifically in these regions (corresponding to such microvilli and microvillar channels) and at present, there is no doubt that issues with microvillar compartments expressing high levels of SR-BI are also active in selective CE uptake [74,75,108110,114-117]. The formation of these specialized microvillar channels appear to be dependent on the presence of SR-BI since these microvillar are quantitatively reduced in adrenals from SR-BI null mice [118]. Conversely, overexpression of SR-BI promotes microvillar channel formation in both steroidogenic and non-steroidogenic cells in vitro $[114,116,117]$. Additionally, SRBI has been functionally associated with caveolae/lipid rafts, although this has not always been the case [74,119124]. SR-BI does show specificity for apolipoproteins, but interacts promiscuously with HDL, LDL, amino acid modified LDL, phospholipids and a variety of other 
ligands $[9,20,105,125,126]$. Hormone treatment or other factors which increase the demand for cholesterol also increase the expression of SR-BI and the influx of lipoprotein cholesteryl esters [74,75,108-110,127]. Deletion of the SR-BI gene in mice resulted in increased circulating levels of HDL-cholesterol, substantially reduced stored tissue cholesterol $[128,129]$, and inhibited the selective uptake, storage, and utilization of cholesterol by steroid-hormone producing cells.

\section{(ii) SR-BI-mediated selective transport of lipoprotein-derived cholesteryl esters}

The mechanism by which SR-BI mediates selective transfer of CE from the cell surface to cell interior is not clearly defined, but may require participation of accessory proteins and lipids, alterations in physicochemical characteristics of the plasma membrane and the physical forms of SR-BI itself. The entire process of "selective" cholesterol ester delivery and its subsequent utilization for steroid synthesis can be broadly divided into three distinct steps, each of which may involve multiple complex processes. The first step in the selective CE uptake is the transfer of lipoprotein-associated $\mathrm{CE}$ to the plasma membrane, the second step entails the translocation of $\mathrm{CE}$ from the plasma membrane to lipid droplets within the interior of the cell; and the third step in the process is the movement of cholesterol from intracellular lipid droplets to mitochondria for steroid hormone synthesis.

Events connected with the SR-BI-mediated transfer of lipoprotein cholesteryl esters to the cell surface--The initial step in the transfer of lipoprotein-cholesteryl esters to the plasma membrane is the binding of cholesterol-rich lipoproteins to the cell surface/microvilli-associated SR-BI followed by release of lipoprotein-cholesteryl esters to the plasma membrane. While SR-BI-lipoprotein interaction is important, it is not sufficient to promote selective transfer of cholesteryl esters to the plasma membrane. This assertion is based on several observations including the fact that mutations of certain glycosylation sites do not affect binding but inhibit selective cholesteryl ester uptake [130]. It has been proposed that SR-BI forms a hydrophobic "channel" through which the cholesteryl esters in SR-BI-associated lipoprotein move down in a concentration gradient manner, and thus, any changes in the structure of the receptor might alter the "channel" without impacting the binding of the lipoprotein [130]. Moreover, it has been suggested that the localization of SR-BI within microvilli or the association of SR-BI with caveolae contributes to the movement of cholesteryl esters into these specialized regions of the plasma membrane.Furthermore, these specialized microvilli/microvillar channel regions and/or caveolae could increase functional efficiency of the transfer process through increased availability of donor particles [111-113]. Limited studies have also suggested the involvement of $\mathrm{C}$-ter- minal and extracellular domain (ECD) domains of SR-BI in the selective cholesterol uptake process [131-134]. Finally, evidence is accumulating suggesting that accessory proteins (see below) and lipids, in addition to SR-BI, contribute to the selective uptake process [135-145].

SR-BI interacting accessory proteins--other significant progress in the area of SR-BI structure and function is the realization that accessory proteins may interact functionally with SR-BI and facilitate the dimerization process, enhance selective HDL-CE uptake and promote cell surface architectural changes. In recent years, one such protein, the PDZ domain containing protein called CLAMP, has been identified with SR-BI mediated selective CE uptake [127]. (The name PDZ is derived from the first three proteins in which these domains were found: PSD$95 \mathrm{Dlg}$, and ZO1; these domains range 70-90 amino acids in length and recognize 3-5 residue motifs that occur at the C-terminus of target proteins or structurally related internal peptide motifs [146-152]). CLAMP was purified from rat liver extracts by affinity chromatography using the last 15 amino acids of the carboxyl terminus of SR-BI, and co-expression of CLAMP, (which is identical to and now referred to as PDZK1 or NHERF3 $[127,141,153,154])$ and SR-BI in CHO cells led to a two-fold increase in selective CE uptake. More recently, Silver by using transgenic animals expressing SR-BI with a mutated PDZK1 interacting domain provided evidence that PDZK1 interacting domain of SR-BI is essential for cell surface expression of hepatic SR-BI in vivo [136]. Also, an endogenous regulator of PDZK1, termed small PDZK1-associated protein (SAP, DD96/MAP17) has been characterized, which when overexpressed in the liver causes increased degradation of PDZK1, resulting in hepatic SR-BI deficiency and markedly increased plasma HDL cholesterol [137].

Krieger and colleagues further demonstrated that targeted disruption of the PDZK1 gene induced hypercholesterolemia, and resulted in substantial reduction of hepatic and intestinal SR-BI, without affecting SR-BI or cholesteryl ester stores in steroidogenic organs [138]. The latter observations are in agreement with the results showing that adrenal and gonads express very low levels of PDZK1 as compared to the liver and strongly suggest the possibility that different types of PDZ-domain containing proteins impact SR-BI in a tissue-specific manner. Interestingly, hepatic expression of SR-BII, a variant with an alternate $\mathrm{C}$-terminal domain, is not affected in PDZK1 knockout mice, suggesting that PDZK1 specifically regulates SR-BI expression and function in the liver. Further studies demonstrated that overexpressing full-length PDZK1 in PDZK1 null mice restored normal hepatic SRBI protein levels [155]. Likewise, hepatic overexpression of wild-type SR-BI restored near or greater than normal levels of functional, cell surface SR-BI protein levels in the 
livers of SR-BI(-/-)/PDZK1(-/-) double knock-out mice and such genetic manipulation restored normal lipoprotein metabolism in the absence of PDZK1 [156]. From these studies, it is concluded that PDZK1 is important for maintaining adequate steady state levels of SR-BI in the liver but is not essential for cell surface expression or function of hepatic SR-BI $[155,156]$. More recent studies indicate that hormone (glucagon)-mediated phosphorylation of the C-terminal region of PDZK1 as well as the presence of all four PDZ domains in PDZK1 is required for normal abundance, localization and, therefore, function of hepatic SR-BI $[157,158]$. More recently, Komori et $a l$, using a transgenic mouse model coexpressing both CLA-1 (human homolog of SR-BI), and human PDZK1 provided evidence that PDZK1 is also an important enhancer of CLA-1 expression in the liver [159]. Besides the liver, a role for PDZK1 is indicated in HDL/SR-BI signaling in endothelium and in the maintenance of endothelial monolayer integrity [142].

Given that PDZK1 is not expressed in steroid producing tissues, coupled with the demonstration that PDZK1 null mice show normal expression of SR-BI in the adrenal gland and ovary, we considered the possibility that additional PDZ domains with specificity for other PDZ proteins may be involved in the regulation of SR-BI function in steroidogenic tissues. We searched for and identified additional Class I, II and III PDZ interacting domains in the $C$-terminal cytoplasmic tail of SR-BI (Table 2) using a simple modular architecture research tool http:// SMART.embl-heidelberg.de. To a large extent these PDZ domains are well conserved among various mammalian species (i.e., mouse, rat, hamster, pig, bovine and human SR-BI), and the Class II PDZ-domain (PDZK1 site) described above is simply the final extreme end site on the SR-BI, which is not well conserved. The function of the other sites is as yet unknown, but it is of interest that the C-terminal domain of SR-BII (the alternative spliced form of SR-BI) lacks terminal PDZ domain and contains entirely different sets of PDZ interacting domains while another family member, CD36 contains no PDZ sites. Interestingly both SR-BII and CD36 are less efficient in mediating selective HDL-CE uptake as compared to SRBI $[131,132]$. We believe these SR-BI PDZ-domain binding motifs may, in fact, be important for steroidogenic tissues--in that they permit binding to a variety of PDZcontaining proteins [146-151]. Indeed, our preliminary Protein Array analysis indicated significant interaction between hCLA-1/SR-BI and PDZ-domain(s) of RGS12, CLP36 (also called hCLIM1 or elfin), RIL, PSD-95, and Mint-3-proteins [160-172]. Among these, RGS12 and RIL, PSD-95 PDZ proteins are known to be highly expressed in steroidogenic proteins $[160,163,170]$. In addition, PDZ-RhoGEF, a novel guanine nucleotide exchange factor (GEF) for Rho-like proteins, contains a
Table 2: Potential Consensus PDZ Domain Binding Sequences in SR-BI, SR-BII and CD36

\begin{tabular}{|c|c|}
\hline \multirow[t]{4}{*}{ Mouse SR-BI: } & QLRSQEKCFLFWSGSKKGSQDKEA \\
\hline & IQAYSESLMSPAAKGTVLQEAKL \\
\hline & QLRSQEKCFLFWSGSKKGSQDKEA \\
\hline & IQAYSESLMSPAAKGTVLQEAKL \\
\hline \multirow[t]{4}{*}{ Rat SR-BI: } & QLRSQEKCFLFWSGSKKGSQDKEA \\
\hline & MQAYSWSLMSPAAKGTVLQEAKL \\
\hline & QLRSQEKCFLFWSGSKKGSQDKEA \\
\hline & MQAYSWSLMSPAAKGTVLQEAKL \\
\hline \multirow[t]{4}{*}{ Hamster SR-BI: } & QLRSQEKCFLFWSGSKKGSQDKEA \\
\hline & IQAYAESLMSPAAKGTVLQEAKL \\
\hline & QLRSQEKCFLFWSGSKKGSQDKEA \\
\hline & IQAYAESLMSPAAKGTVLQEAKL \\
\hline \multirow[t]{4}{*}{ Rabbit SR-BI: } & QVRSQEKCYLFWSGSKKGSKDKEA \\
\hline & IQAYSESLMTPDPKGTVLQEARL \\
\hline & QVRSQEKCYLFWSGSKKGSKDKEA \\
\hline & IQAYSESLMTPDPKGTVLQEARL \\
\hline \multirow[t]{4}{*}{ Pig SR-BI: } & QIRSQEKCYLFWSSSKKGSKDKEA \\
\hline & IQAYSESLMTPAPKGTVLQEARL \\
\hline & QIRSQEKCYLFWSSSKKGSKDKEA \\
\hline & IQAYSESLMTPAPKGTVLQEARL \\
\hline \multirow[t]{4}{*}{ Cow SR-BI: } & QIRSQEKCYLFWISFKKGSKDKEA \\
\hline & VQAYSEFLMTSPPKGTVLQEARL \\
\hline & QIRSQEKCYLFWISFKKGSKDKEA \\
\hline & VQAYSEFLMTSPPKGTVLQEARL \\
\hline \multirow[t]{4}{*}{ Human SR-BI: } & QIRSQEKCYLFWSSSKKGSKDKEA \\
\hline & IQAYSESLMTSAPKGSVLQEAKL \\
\hline & QIRSQEKCYLFWSSSKKGSKDKEAI- \\
\hline & QAYSESLMTSAPKGSVLQEAKL \\
\hline \multirow[t]{3}{*}{ Mouse SR-BII: } & QLRSQGPEDTISPPNLIAWSDQPP \\
\hline & SPYTPLLEDSLSGQPTSAMA \\
\hline & $\begin{array}{l}\text { QLRSQGPEDTISPPNLIAWSDQPPS } \\
\text { PYTPLLEDSLSGOPTSAMA }\end{array}$ \\
\hline Rat CD36: & RSKNGK-None \\
\hline \multicolumn{2}{|c|}{$\begin{array}{l}\text { PDZ Domain-Class I: S or T-X-I, V, L or M; PDZ Domain-Class II: } \boldsymbol{\Psi} \text { - } \\
\mathbf{X}-\boldsymbol{\Psi} \text {; PDZ Domain-Class III: } \mathbf{D} \text { or } \mathbf{E}-\mathbf{X}-\boldsymbol{\Psi} \text {. The C-terminal residue } \\
\text { is referred to as Po residue; subsequent residues towards the N- } \\
\text { terminus are termed P-1, P-2, P-3 etc. } \mathbf{X} \text { denotes any amino acid } \\
\text { (no specificity defined at this position for this class). } \boldsymbol{\Psi} \text { denotes a } \\
\text { hydrophobic amino acid usually V, I or L. The sequences of C- } \\
\text { terminal domain of SR-BI, SR-BII and CD36 are presented in } \\
\text { duplicates to accomodate } 3 \text { letter overlapping combinations of } \\
\text { putative PDZ binding sites. The putative PDZ domain binding } \\
\text { sequences (three letters) are shown as bold letters. }\end{array}$} \\
\hline
\end{tabular}

PDZ domain which shows high affinity for the actin cytoskeleton, and is also highly expressed in various steroidogenic tissues $[173,174]$.

Additionally, using a transient overexpression strategy, we directly examined the effect of a number of PDZ domain containing proteins on SR-BI-mediated selective 
HDL-CE uptake in representative steroidogenic (MLTC, mouse testicular Leydig cells) and hepatic (HepG2, human hepatoma cells) cell lines. Co-transfection with PDZ proteins, DLG3, DLG5, or PDLIM1 plus SR-BI significantly increased selective HDL-CE uptake in both HepG2 and MLTC cells as compared to cells transfected with SR-BI alone. Moreover, several additional PDZ proteins such as GOPC, HTRA2, INADAL, LIN7B, MAG12, MAG13, MAST2 and PARD6B variably, but significantly enhanced selective HDL-CE uptake. In contrast, expression of other PDZ domains containing proteins including DVL1, DLV3, LIN7C, MPP2, DLG2, DLG3, or GRIP1 showed no demonstratable effect on SR-BI-mediated selective HDL-CE uptake. These data led us to conclude that steroidogenic cells, like hepatocytes, require the participation of PDZ type proteins for the maximal functional efficiency of SR-BI, but show a wide specificity towards PDZ proteins. However, at present, a number of important questions remain unanswered. For example, it is unclear how these various proteins regulate SR-BI function, whether they are expressed in steroidogenic cells, and their expression, like SR-BI, is regulated by tropic hormones and whether different PDZ proteins differentially impact SR-BI function in different steroidogenic cell types (i.e., adrenal, ovarian and testicular cells).

SR-BI-mediated alterations in the lipid composition of plasma membranes--It has been suggested that SR-BI may alter the composition of lipid domains of plasma membranes which then leads to changes in free cholesterol flux, changes in membrane cholesterol content, changes in plasma membrane phosphatidylcholine subspecies or in altered physical/chemical properties of the membrane [143,144]. In another study, Chen et al. reported that expression of SR-BI in RAW macrophages markedly reduced ABCA1-mediated cholesterol efflux to apolipoprotein A1 presumably by sequestering cholesterol that is normally available to ABCA1 for efflux [145]. On the other hand, it is demonstrated that sphingomyelin and ceramide in the lipoproteins and the cell membranes regulate the SR-BI-mediated selective uptake of CE in SR$\mathrm{BI}$ transfected CHO cells, hepatocytes (HepG2) and adrenocortical cells (Y1BS1), possibly by interacting with the sterol ring or with SR-BI itself [140]. Our recent studies suggest that SR-BI may also be involved in the regulation of cell surface expression of microvillar channel formation, a function that may increase the functional efficiency of the selective CE uptake process through increased trapping and binding of HDL at the cell surface $[114,116,117]$.

SR-BI dimerization--the physical form of SR-BI may also play an important role in its ability to mediate selective CE transport. Indeed, it is becoming increasingly clear that hormone-induced changes in tissues--which alter the expression of SR-BI, alter selective CE uptake in the same tissues, and correspondingly produce architectural changes in the cell surface of affected cells--also show changes in 'dimerization' of SR-BI in cell or tissue samples (for simplicity, we use the term dimerization here to include the multiple forms of the SR-BI protein; i.e., dimers, and higher order oligomers). In one of the earliest direct demonstrations of protein-protein interaction involving SR-BI, our laboratory demonstrated (by SDS PAGE-Western blotting) that SR-BI exists as homodimers in $17 \alpha$-ethinyl estradiol $\left(17 \alpha-\mathrm{E}_{2}\right)$ primed and microvilli-enriched rat adrenal plasma membrane [109]. In subsequent studies, we were able to demonstrate that SR-BI exists in dimeric and high order oligomeric forms in all cells and tissue which are active in 'selective' uptake of HDL-CEs (e.g., hormone activated steroidogenic tissues such as mouse adrenal, testis, and ovary; steroidogenic cells such as rat ovarian luteal cells, Y1-BS1 mouse adrenocortical cells, R2C rat Leydig cells, and MLTC mouse Leydig cells; liver from SR-BI transgenic mice; SR-BI overexpressing non-steroidogenic cells such as HEK 293, Y1-BS1, CHO and COS cells; Sf9 insect cells programmed to express rat SR-BI [114,116,117]. Early functional evidence for SR-BI dimerization came from the observation that in normal rat adrenal tissue, SR-BI exists primarily in the monomeric form with some dimer formation. ACTH stimulation increased the dimerization of SR-BI in this tissue along with increased selective CE uptake, and dexamethasone-induced loss of ACTH led dramatically to the loss of SR-BI, SR-BI dimers and selective HDL-CE uptake $[109,116]$. These results are coupled with striking architectural changes of the microvillar compartment at the adrenocortical cell surface, and suggest that SR-BI dimers may, in a very basic way, be associated with SR-BI sites of action and function.

Additional functional evidence came from our laboratory showing a strong correlation from the levels of SR-BI dimers and increased selective HDL-CE uptake in cells and tissues (Fig. 4), and from co-immunoprecipitation studies of epitope-tagged SR-BIs (SR-BI-cMyc and SR-BIV5) used to demonstrate that SR-BI can exist as homodimers [116]. The use of cross-linking agents further confirmed that SR-BI forms dimers in native steroidogenic cell lines (endogenous), as well as in a heterologous insect cell expression system [114]. Also, analysis of cellular extracts from SR-BI transfected HEK-293 cells or ACTHtreated Y1-BS1 cells by size-exclusion chromatography and sucrose density centrifugation demonstrated that a significant portion of SR-BI exists in dimeric and oligomeric forms. As an independent measure, we have utilized immunoelectron microscopy which further provides convincing evidence for the formation of SRBI:SR-BI homodimers. We showed that when double tagged-SR-BI proteins (SR-BI-cMyc and SR-BI-V5) are co-expressed in HEK-293 cells and the different proteins 
are subsequently immunostained and identified with two differently stained gold particles, there is mixing and clustering of gold particles suggesting 1 ) that the proteins travel to the same cell location, and 2) that many of the gold particles are in exceedingly close physical contact, i.e., within the distance accepted for protein dimers by fluorescent resonance energy transfer (FRET) technique $[116,117]$. Similar results were obtained when Y1-BS1 mouse adrenocortical cells were transfected with V5 and/ or cMyc tagged-SR-BI proteins. Interestingly, SR-BI transfected Y1-BS1 demonstrated major architectural changes along with the formation of double membranes in flower like arrangements. Gold-labeled secondary antibodies against V5 or cMyc antibody localized SR-BI to these sites, and revealed substantial dimer formation of this protein--shown by close contact between gold particles $[116,117]$.

From the above discussion it is apparent that while the understanding of the functional significance of SR-BI dimerization in steroidogenic tissues and cell lines which utilize the selective pathway for cholesterol transport is improving, the structural basis of the intramolecular interactions involved in SR-BI dimerization and function is not completely understood. In particular, the information about the contribution of the extracellular domain (ECD) of SR-BI either independently or in cooperation with the $C$-terminal domain on SR-BI dimerization, SRBI-induced microvillar channel formation, and selective HDL-CE uptake remains sketchy. In an effort to further expand our understanding about the structure-function relationships and dynamics of SR-BI activity, we recently carried out studies aimed at determining the structural and functional contributions of cysteine residues within the SR-BI. We focused our efforts on cysteine residues because: (a) cysteine residues are integral for inducing and maintaining the three-dimensional confirmation in proteins by forming critical inter- and intra-molecular disulfide bond linkages; (b) sulfhydryl ( $\mathrm{SH}$ ) side chains of cysteins are polar similar to that of the hydroxyl group $(\mathrm{OH})$ of serines and can participate in hydrogen bonding interactions and facilitate protein-protein interactions; (c) cysteine side-chains are preferred sites for various biological coupling and conjugation reactions such as palmitoylation, isoprenylation, disulfide cross-linking, and thiol-disulfide exchange which are known to play critical roles in intracellular protein trafficking, stability and/or activity; and (d) the SR-BI contains several cysteine residues that are highly conserved across the species and uniquely distributed within the different domains of the SR-BI molecule and as such are highly likely to contribute towards SR-BI structure and function [175-179].

We chose to study the rat SR-BI because it contains more conserved cysteine sequences than SR-BI from any other species. Its sequence contains a total of eight cysteine (C) residues (C21, C251, C280, C321, C323, C334, C384, and C470). With the exception of C21, the remaining seven residues are highly conserved in other species including the mouse, hamster, rabbit, pig, cow, dog, tree shrew and human. Five residues (C280, C321, C323, C334, and C384) are clustered in the C-terminal half of the putative extracellular domain (ECD). The remaining three cysteine residues are equally distributed in the N-terminal transmembrane domain (C21), N-terminal half of the ECD (C251), and the C-terminal domain (C470). Given that the extracellular domain contains six conserved cysteine residues, these could form up to three disulfide bonds, which in turn could help to stabilize the confirmation of SR-BI or participate in its dimerization. We replaced these cysteine residues with serine (S) singly or in pairs, expressed the mutated SR-BI constructs in $\mathrm{CHO}$ or COS-7 cells and examined the impact of these mutations on SR-BI expression and function. Overall, these studies indicated that C280S, C321S, C323S and $\mathrm{C} 334 \mathrm{~S}$ residues of the extracellular domain (ECD) are necessary for preserving normal SR-B (HDL) binding activity, selective CE uptake, and/or cell surface expression. Interestingly, mutation of any of these four cysteine residues to serine resulted in a robust induction of SR-BI dimer formation, but they are rendered non-functional because these residues are most likely also essential for the optimal HDL binding and hence, the selective CE uptake.

\section{(iii) Translocation of cholesteryl esters/cholesterol from cell surface (plasma membrane) to lipid droplets}

Although selective uptake of cholesteryl esters for all practical purposes is considered to be non-endocytic, at least from the point of view of uptake of the intact lipoprotein particle, there are controversies regarding cholestryl ester movement to lipid droplets. However, there are some suggestions that HDL-cholesteryl esters are delivered to the cell interior by the retero-endocytosis, where the receptor-bound HDL particle analogous to the transferrin receptor system is internalized, traverses an intracellular pathway during which cholesteryl esters are transferred to the cell interior and the HDL particle is recycled back to the plasma membrane where the lipid depleted HDL is now released [180-185]. This possibility appears to be weak given the overwhelming morphological evidence both at the light- and electron microscopic evidence showing that in vivo and in vitro HDL-cholesteryl ester delivery to adrenal and ovarian luteal tissues and cultured cells, respectively, does not involve internalization of the intact HDL particle itself, $[73,90,100,101,103,186,187]$. It is possible that a small amount of HDL internalization in cultured cells reported by some investigators was in fact due to non-specific 


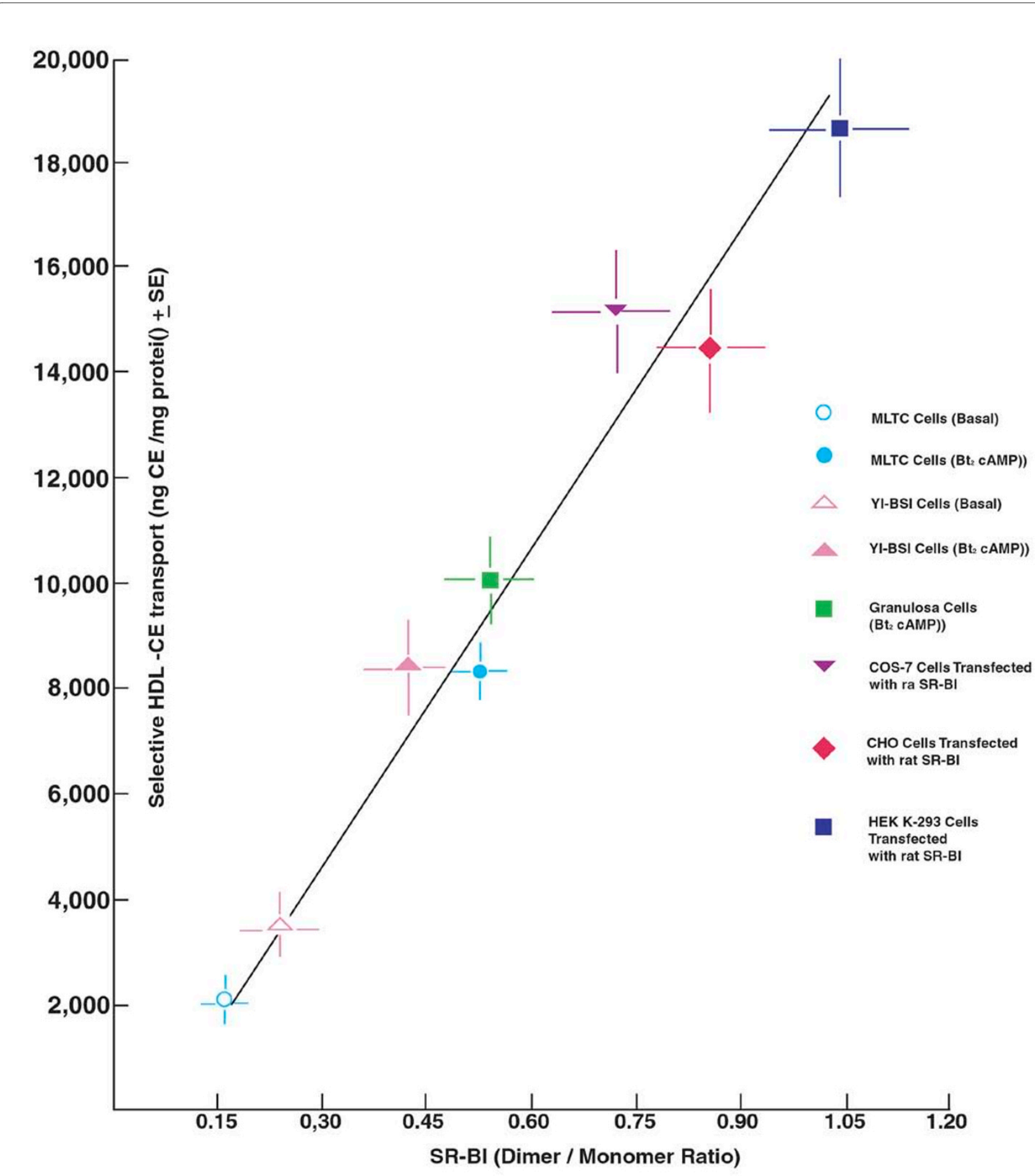

Figure 4 Correlation between the cellular levels of SR-BI dimers and the functional efficiency of selective HDL-CE uptake. Appropriate Western blots from various cell types were scanned for SR-BI monomers and dimers and dimer/monomer ratios were plotted against the respective selective HDL-CE uptake data. The results show that dimer/monomer ratios determined for individual cell types correlate significantly with their respective SR-BI-mediated selective HDL-CE uptake.

endocytosis of the HDL particle; indeed, there is considerable in vitro evidence that cultured cells can internalize a variety of receptor ligands in a non-specific manner [188-191]. It has also been suggested that HDL- cholesteryl esters are delivered to intracellular membranes via the formation of complexes with caveolin, annexin and cyclophilins [192]. In this regard, it is noteworthy that caveolin is a component of several intracellular vesicle populations, caveolin-1 is required for lipid droplets for- 
mation, and all forms of caveolins (i.e. caveolin-1, -2 and 3) can associate with lipid droplets [193-197].

Lipid droplets are associated with proteins involved in vesicle-vesicle targeting and the fusion process in the cells including $N$-ethylmaleimide (NEM)-sensitive factor (NSF), soluble NSF attachment protein (alpha-SNAP), and the SNAP receptors (SNAREs), synaptosomal-associated protein of $23 \mathrm{kDa}$ (SNAP23), syntaxin- 5 and vesicleassociated membrane protein 4 (VAMP4), a chaperone protein that participates in [198]. In this context our own studies have shown that treatment of steroidogenic cells with NEM, an inhibitor of NSF, results in a total block of HDL-derived selective cholesteryl ester uptake $[72,73]$. Thus, intracellular transport of cholesteryl esters to lipid droplets might involve active participation of carrierand/or vesicle-mediated cholesterol transport processes. On the other hand, $75 \%$ of SR-BI delivered HDL-cholesteryl esters were reported to be hydrolyzed by non-lysosomal neutral cholesteryl ester hydrolases (nCEHs) suggesting that freshly delivered cholesteryl esters could also be transported in the form of free cholesterol to various cellular destinations [199]. Existing literature also supports this possibility given that fatty acid composition of cholesteryl esters in the rodent adrenal and ovary is significantly different from that of plasma or HDL, i.e., this could only occur if internalized plasma lipoproteinderived cholesterol esters were at first hydrolyzed and then ensuing free cholesterol re-esterified with fatty acids to a defined fatty acid composition that is unique and specific for each of the steroidogenic tissues [200-203]. A combination of vesicular and non-vesicular transport processes most likely facilitates the transport of the newly released free cholesterol to the ER for its esterification and subsequent storage in lipid droplets $[55,57,66,204]$. Depending on cellular needs, free cholesterol could also be redirected to the plasma membrane or mitochondria (for steroid synthesis), again possibly via vesicular and/or non-vesicular transport pathways $[55,57,66,204]$.

\section{Intracellular cholesterol processing and its transport to mitochondria for the initiation of steroid synthesis}

Steroid producing cells through the use of multiple cholesterol supply sources discussed above maintain adequate cholesterol reserves primarily in the form of lipid droplets that enable them to quickly respond to tropic hormone stimulation with the rapid mobilization of cellular cholesterol reserves and ensuing transport to mitochondria for steroidogenesis. In adrenal and ovarian cells, cellular stores of cholesterol esters are constantly replenished by the delivery of plasma cholesterol through endocytic or selective pathway (depending on species and lipoprotein type), whereas this chore in Leydig cells, under normal physiological conditions, is mainly achieved through increased de novo cholesterol synthesis. During acute hormonal stimulation, these endogenously stored cholesterol esters are rapidly mobilized (hydrolyzed) and released free-cholesterol is efficiently transported to and within the mitochondria for its conversion to pregnenolone, the precursor of all steroid hormones. This entire process involving the intracellular cholesterol mobilization, processing and transport to the appropriate site within the mitochondria for side-chain cleavage and pregnenolone production can be broadly divided into two separate, but equally important segments: a) mobilization of cholesterol from intracellular stores, particularly from lipid droplets; b) transport of mobilized cholesterol to the outer mitochondrial membrane; and c), transfer of this cholesterol from the outer to the inner mitochondrial membrane. In the following sections, we will discuss characteristics of these three segments of intracellular cholesterol transport and also summarize current understanding about the functional roles of key proteins and factors involved in the mobilization of cellular cholesteryl esters, intracellular transport of newly released cholesterol to the outer mitochondrial membrane and its subsequent translocation to the inner mitochondrial membrane for the initiation of steroidogenesis.

\section{(a) Mobilization of cellular cholesterol reserves in response} to acute hormonal stimulation

It is well known that adrenal, ovarian and testicular Leydig cells' cholesteryl esters are rapidly depleted following tropic hormone (ACTH, LH/hCG) treatment supporting the notion that mobilization of lipid droplets (LD) stored cholesteryl esters provides cholesterol for acute hormonal stimulation of steroid synthesis [205-207]. This mobilization of substrate cholesterol occurs through tropic hormone-mediated increased formation of second messenger, cAMP followed by activation of PKA, and PKA-mediated phosphorylation (activation) of neutral cholesteryl ester hydrolase ( $\mathrm{nCEH})$, resulting in rapid hydrolysis of cholesteryl esters [21-24,24,78-80,205-210]. We reported that hormone-sensitive lipase (HSL) is responsible for the vast majority, if not all, of nCEH activity in the adrenal [208]. This was based on the observation that inactivation of HSL resulted in the loss of $>98 \%$ of nCEH [208]. Moreover, we reported that adrenocortical cells isolated from HSL null mice show almost complete inhibition of ACTH stimulated and HDL-supported corticosterone secretion (>99\%) as compared to cells isolated from control mice, further demonstrating the importance of HSL in adrenal steroidogenesis; HSL null mice also show an increased lipid accumulation in the adrenals and a blunted corticosterone secretion in vivo $[209,210]$. Current evidence also suggests that HSL is likely to function as a cholesteryl ester hydrolase in the 
ovary [211-213]. There is also a testis-specific isoform of HSL with a molecular mass of $120 \mathrm{kDa}$ [80-82]. This isoform differs from a more common isoform of HSL, which is expressed in adipose tissue and adrenal, ovary and other tissues/cells, by containing some additional 300 amino acids [213-215]. This $120 \mathrm{kDa}$ isoform is predominantly expressed in germ cells of the testis and its expression is hormonally regulated [216]. However, the identity and expression of HSL in testosterone producing testicular Leydig cells has yet to be established.

\section{(b) Transport of mobilized cholesterol to the outer mitochondrial membrane}

The newly released cholesterol is transported to the outer mitochondrial membrane (OMM) for the production of steroid hormones. Because cholesterol is a hydrophobic molecule and diffuses poorly in an aqueous environment, it can traverse from the cytoplasmic locations to the OMM by several potential mechanisms [54-57,66]. Cholesterol can be transported via the vesicular transport mechanism, i.e., it can be incorporated into the vesicular structures involved in cellular trafficking (e.g., transport vesicles, endosomes, and secondary lysosomes) which then fuse either directly or indirectly (through other intermediary membranes) fuses with mitochondria and deliver their cargo to the OMM. However, this pathway appears to play a minor role $[55,84]$. Cholesterol may also be delivered to OMM via protein-protein interactions between the lipid droplets and mitochondria. As early as in 1975, electron microscopic observations provided evidence suggesting that lipid droplets become juxtaposed during stimulation by tropic hormone [217]. In the last few years, additional evidence has emerged showing potential interactions between lipid droplets and cellular organelles including mitochondria in several cell systems [69,218-220]. More recently, Boström et al reported the presence of some constituent proteins of the SNARE complexes on the lipid droplets [198]. (SNARE complexes facilitate fusion between transport vesicles and target membranes during protein trafficking) [221-223]. These proteins include, NSF, $\alpha$-SNAP, and SNAREs, SNAP23, syntaxin-5, and VAMP4. The authors of this report also provide evidence that VAMP4, syntaxin5 and SNAP23 are required for lipid droplet fusion [198]. More recently, another report provided direct evidence showing that the SNAP23 protein promotes interaction between lipid droplets and mitochondria [224]. Other reports suggest that steroidogenic cells express high-levels of some members of SNARE proteins such as Syntaxin-17 SNAP23, and SNAP25, and that expression of the neuronal type of SNAP25 is hormonally regulated in ovarian granulosa cells [225-229]. These various observations strongly suggest that SNARE proteins may mediate the transport of cholesterol substrate from lipid droplets to steroidogenic mitochondria, most likely by promoting the functional interaction between lipid droplets and mitochondria.

A second potential mechanism by which mobilized cholesterol from lipid droplets may be delivered to the mitochondrial for steroid synthesis is through a nonvesicular transport process involving high-affinity cholesterol binding proteins $[55,57,66,84,230]$. Earlier studies indicated that sterol carrier $\operatorname{protein}_{2}\left(\mathrm{SCP}_{2}\right)$, a nonspecific lipid transfer protein, mediates cholesterol transport to steroidogenic mitochondria and also stimulates steroid hormone biosynthesis [230-232]. Contrary to these findings, more recent metabolic and genetic evidence suggests that $\mathrm{SCP}_{2}$ mainly functions as a carrier for fatty acyl CoAs, facilitates branched-chain fatty acid oxidation and regulates the distribution of key lipid signaling molecules (e.g., FA, fatty acyl CoAs, LPA, PI and sphingolipids) between lipid rafts/caveolae and intracellular sites, while it appears to play a minor role in cellular cholesterol trafficking primarily because of its very low affinity for cholesterol [233,234]. More recently, Breslow's laboratory has identified a subfamily of lipid binding proteins referred to as StarD4, StarD5 and StarD6 (StarD4 subfamily) $[235,236]$, which are structurally related to steroidogenic acute regulatory protein (StarD1/StAR), a prototype of the steroidogenic acute regulatory-related lipid transfer (START) domain containing a superfamily of proteins [84,235-238]. StarD4 and StarD5 are widely expressed in steroid producing cells, while StarD6 expression appears to be mostly restricted to the testicular germ cells $[239,240]$. In contrast to StarD1 and StarD3/MLN64, StarD4, StarD5 and StarD6 lack any signal peptides, and thus, they are not targeted to any specific cellular organelles. Therefore, they are considered to be a cytosolic protein like StarD2/PCTP [238,239]. Interestingly, StarD6 despite lacking any $\mathrm{N}$-terminal target sequences that should direct this protein to mitochondria is reported to have physicochemical properties and biological activity (stimulation of steroidogenesis) similar to that of StarD1/ StAR, while StarD4 and StarD5 exhibit low levels of StarD1/StAR-like activity [240]. Both StarD4 and StarD5, however, bind free cholesterol with high-affinity and specificity, facilitate cholesterol transport through an aqueous environment and have been shown to play important roles in the maintenance of cellular cholesterol homeostasis [241,242]. The ability and specificity of StarD4 and StarD5 to bind cholesterol, coupled with their high levels of expression in steroidogenic tissues, raises the strong possibility that StarD4 and StarD5 facilitate cholesterol transport to the outer mitochondrial membrane. However, confirmation of this possibility must await the relevant experimental evidence.

Extensive but mostly circumstantial evidence suggests that cellular architecture and cytoskeletal elements, in particular, vimentin-intermediate filaments (IF, Type III) 
may also be involved in facilitating cholesterol transport to mitochondria $[8,243,244]$. Vimentin-intermediate filament constitutes part of the network of the cytoskeleton [245]. It is expressed in many cell types including adrenal, ovarian and testicular Leydig cells [245-250]. Several different reports of proteomic analyses of lipid droplets isolated from cells have consistently identified vimentin as a lipid droplet associated protein [251-253]. Vimentin has been shown to interact with several different proteins, including some motor-like propertiesand sterol binding properties [254-256]. Using a proteomics approach, vimentin was identified as an interacting partner of agonist stimulated $\beta_{3}$-adrenergic receptors and this interaction was shown to be important for activation of ERK and stimulation of lipolysis, providing the additional involvement of vimentin in lipid droplet metabolism [257]. The overexpression of ORP4, which interacts with vimentin and causes its aggregation, results in a defect in cholesterol esterification [254]. Likewise, adrenal cells lacking vimentin display a defect in the re-esterification of LDL cholesterol without any alterations in LDL-receptormediated endocytosis [258]. Hall and colleagues reported a close association of both functional mitochondria and cholesterol-enriched lipid droplets with the intermediate filaments in Y1 adrenal tumor cells, and testicular Leydig cells and suggested the possibility that such binding may facilitate the transport of cholesterol to mitochondria for steroid synthesis [248-250]. Furthermore, binding of lipid droplets and mitochondria to vimentin-intermediate filaments may also provide an ideal platform for docking of lipid droplets to the mitochondria and secondarily increased cholesterol transport to mitochondria. Besides morphological evidence, a number of biochemical studies employing pharmacological inhibitors raised the possibility that cytoskeletal elements including vimentin may contribute to the cholesterol transport to mitochondria and the regulation of steroidogenesis although conflicting results have been generated [243]. Also, it is important to realize that agents which were previously used in many of these studies to disrupt microfilaments, e.g., nocadazole, cytochalasin, and cyclohexamide, affect tubulin and actin, but have no effects on vimentin [259]. Obviously, more experimental work is needed to clearly define the role of cytoskeletal elements/structures including vimentin intermediate filaments in cholesterol transport to mitochondria and regulation of steroidogenesis.

(c) Translocation of cholesterol from the outer mitochondrial membrane to the inner mitochondrial P450scc site

The second critical step in steroid hormone biosynthesis is delivery of the cholesterol substrate to the inner mitochondrial membrane (IMM) sites, where cholesterol sidechain cleavage P450scc is located, and the enzyme that catalyzes the conversion of cholesterol to pregnenolone takes place $[3-6,8]$. This step is rate-limiting because the hydrophobic cholesterol cannot freely diffuse through the aqueous intermembrane space of the mitochondria to support acute steroid synthesis and requires the participation of a de novo synthesized labile protein $[8,47-$ 50,260-264]. This putative labile protein evaded detection for almost twenty years until 1983 when Orme-Johnson's laboratory first demonstrated that acute ACTH stimulation of adrenocortical cell steroidogenesis was accompanied by a rapid induction of $37 \mathrm{kDa}$ phosphoprotein [265]. Subsequent studies from her laboratory provided further characterization of this phosphoprotein in the adrenal and also demonstrated its presence and hormonal induction in corpus luteum and testicular Leydig cells [266-272]. Stocco and colleagues confirmed these observations in MA-10 Leydig tumor cells, and subsequently cloned this protein and named it steroidogenic acute regulatory protein (StAR) [273,274]. StAR has been cloned from many species and is highly conserved across the species [275]. StAR protein possesses all of the necessary characteristics of the acute regulator of steroid synthesis in steroidogenic cells i.e., its synthesis is specifically induced in steroidogenic cells of the adrenal and gonads in response to tropic hormone, is highly labile, and is sensitive to the protein synthesis inhibitor, cycloheximide [8,23,84,264-273].

The role of StAR protein in the regulation of acute hormonal steroidogenesis was supported by three lines of evidence. First, transfection of a model testicular Leydig cell line (MA-10 cells) with a StAR plasmid stimulated steroid production to the same extent as that seen with a maximum stimulating dose of cAMP analog [274]. Second, co-transfection of StAR plus a fusion protein complex of P450scc plasmids in a heterologous cell system produced several-fold more pregnenolone (steroid) as compared to cells transfected with P450scc fusion complex alone [276,277]. Third, the most compelling evidence for a role of StAR in steroiodogenesis was provided by demonstrating that mutations in the StAR gene cause a fatal condition in newborns, the congenital lipoid adrenal hyperplasia (lipoid $\mathrm{CAH}$ ), characterized by severe impairment of steroiodogenesis, hypertrophied adrenals containing high levels of cholesterol esters and free cholesterol and increased amounts of neutral lipids in the testicular Leydig cells $[276,278]$. Depletion of the murine StAR gene by homologous recombination yielded an identical phenotype of impaired steroidogenesis and lipid accumulation in the adrenal and gonads $[279,280]$.

In accordance with its role in the acute regulation of steroidogenesis, StAR is expressed mainly in the adrenal cortex, steroid producing cells of the ovary and testicular Leydig cells [277,281]. Significant expression of StAR is also reported in the rodent brain cell type that parallels 
the expression of P450scc and other steroidogenic enzymes, but its potential role in neurosteroidogenesis is not yet established [84]. In contrast, StAR expression is not detected in another major steroidogenic tissue, the placenta, which secretes progesterone constitutively $[277,281]$. StAR is synthesized as a short-lived cytoplasmic $37-\mathrm{kDa}$ protein with a mitochondrial targeting peptide that is cleaved upon mitochondrial import to yield the long-lived intramitochondrial $30-\mathrm{kDa}$ form $[84,269,273]$. StAR functions as a sterol transfer protein, binds cholesterol, mediates the acute steroidogenic response by moving cholesterol OMM to IMM, acts on the OMM, and requires structural change previously described as a pH-dependent molten globule [282-287]. StAR is also a prototype of a family of proteins that contain StAR-related lipid transfer (START) domains (StarD proteins), of which StarD3/MLN64, StarD4, 5 and 6 exhibit steroidogenic potential [235,236,238,240,282287].

Given that StAR (StarD1) acts on the outer membrane in mediating the transfer of cholesterol from the OMM to the IMM, and raises the possibility that it may be a component of a multi-protein complex [84,284-289]. Several lines of evidence indicate that peripheral-type benzodiazepine receptor (PBR) is also involved in mitochondrial import of cholesterol substrate [290,291]. PBR, which is now referred to as translocator protein (18 kDa, TSPO) is a high-affinity drug- and cholesterol-binding mitochondrial protein, with a cytoplasmic domain containing a cholesterol recognition amino acid consensus (CRAC) domain [292]. TSPO is expressed ubiquitously in the OMM, but is more abundant in the adrenal gland and steroidogenic cells of gonads [288,289,291-296]. TSPO ligands stimulate steroid synthesis and promote translocation of cholesterol from OMM to the IMM in testicular Leydig cells, ovarian granulosa cells, and adrenocortical cells [290,291,293-298]. Mutagenesis of the CRAC domain interferes with cholesterol binding and transfer of cholesterol to IMM [299,300]. Targeted deletion of the TSPO gene in a Leydig cell line (TSPO-deficient R2C cells) blocked cholesterol transport into the mitochondria and dramatically reduced steroid production, whereas reintroduction of TSPO in the deficient cell line restored the steroidogenic capacity [301]. TSPO is a component of a $140-200 \mathrm{kDa}$ multi-protein complex consisting of 18-kDa TSPO itself (and its polymorphic form), the $34-\mathrm{kDa}$ voltage-dependent anion channel (VDAC), the $30-\mathrm{kDa}$ adenine nucleotide translocator (ANC), a $10-\mathrm{kDa}$ protein (pk 10), TSPO-associated protein-1 (PRAX-1), and the TSPO and protein kinase A (PKA) regulatory subunit RI $\alpha$-associated protein (PAP7) [288].

Increasing evidence now suggests that TSPO and StAR interact functionally in mediating the transfer of cholesterol from the outer mitochondrial membrane to the inner mitochondrial membrane. For example, FRET measurements indicated that StAR and TSPO come within the $100 \mathrm{~A}^{\circ}$ of each other consistent with the possibility that StAR and TSPO may interact with each other [302]. However, using a complementary bioluminescence resonance energy transfer, the same laboratory was unable to provide evidence for protein-protein interaction between TSPO and StAR [303]. Hauet et al provided evidence that isolated mitochondria from Tom 20/StAR overexpressing MA-10 Leydig cells produced steroids at a maximal level, but these cells lose their steroidogenic capacity if exposed to TSPO-antisense oligonucleotide [304]. Interestingly, re-introduction of recombinant TSPO into the mitochondrial environment in vitro restored the steroidogenesis [304]. The current thinking is that functional cooperation between proteins such as the cAMP-dependent protein kinase regulatory subunit $\alpha$ (PKA-RI $\alpha$ ) and the PKA-RI $\alpha$ - and TSPO-associated acyl-coenzyme a binding domain containing 3 (ACBD3) proteins, PAP7, cholesterol is transferred to and docked at the OMM [288]. The TSPO-dependent import of StAR into mitochondria, StAR interaction with VDAC1, and phosphate carrier protein $(\mathrm{PCP})$ on the $\mathrm{OMM}$, and the association of TSPO with the outer/inner mitochondrial membrane contact sites, drives the intramitochondrial cholesterol transfer and subsequent steroid formation [288].

\section{Conclusions}

Steroid producing cells have a dual requirement for cholesterol: they need cholesterol for membrane biogenesis and cell signaling as well as starting material for the mitochondrial synthesis of pregnenolone, the precursor steroid required for the formation of glucocorticoids, mineralocorticoids, and sex-steroids. For steroid hormone production to proceed normally, adequate cholesterol must be available and supplied to the mitochondria. Under most physiological conditions, the supply of cholesterol is not rate-limiting, because there are multiple pathways that can fulfill the cholesterol needs of the cell. Although cellular de novo cholesterol synthesis and cholesteryl esters stored in lipid droplets can potentially supply adequate amounts of cholesterol substrate to support steroidogenesis, adrenal and ovary (and testicular Leydig cells under certain conditions), they however, preferentially utilize plasma lipoprotein-derived cholesterol for steroid synthesis. All steroidogenic cells irrespective of species have the capability to acquire cholesterol from plasma LDL, or other apolipoprotein B- (apoB) or apoEcontaining lipoproteins via the well-characterized LDL (B/E) receptor-mediated endocytic pathway. Its functional efficiency, however, is dictated by the physiological status of the steroidogenic cell, the species and the type and composition of circulating lipoproteins. Steroidogenic cells can also process exceptionally large quantities 
of lipoprotein-derived cholesteryl esters through the "selective" cholesteryl ester uptake pathway. Indeed, the "selective" cholesterol uptake pathway is quantitatively the most important source for cholesterol delivery for steroidogenesis in the tropic-hormone stimulated rodent adrenal and ovary. The "selective" cholesterol uptake pathway involves internalization of cholesteryl esters from cell surface bound cholesterol-rich lipoproteins (HDL or LDL, regardless of lipoprotein composition) without the parallel uptake and lysosomal degradation of the lipoprotein particle itself. Hormone regulatable scavenger receptor class $B$, type I (SR-BI) is a physiologically relevant cell surface receptor responsible for "selective" uptake of lipoprotein-derived cholesteryl esters. The mechanisms by which plasma-lipoprotein cholesterol is delivered to steroidogenic cells via the SR-BI mediated "selective" uptake pathway has been extensively studied, but remains incompletely understood. Based on the current evidence, it appears that selective transfer of cholesterol esters to plasma membrane and their subsequent delivery to the cell interior by SR-BI requires the participation of accessory proteins, alterations in physicochemical characteristics of the plasma membrane (e.g., microvillar channel formation, caveolae/membrane lipid raft, lipid domain) and the specific physical form of SR-BI itself (dimerization, oligomerization).

The second step in cholesterol utilization for steroid hormone synthesis is intracellular cholesterol mobilization and processing and transport to the appropriate site within the mitochondria for side-chain cleavage and pregnenolone production. This process can be broadly divided into three separate, but equally important segments: a) tropic hormone-induced mobilization of cholesterol from intracellular stores, particularly from lipid droplets, transport of newly released free cholesterol to the outer mitochondrial membrane; and b) transfer of this cholesterol from the outer to the inner mitochondrial membrane for steroid (pregnenolone) production. Tropic hormone-mediated increased formation of the second messenger, cAMP, stimulates cAMP-PKA resulting in activation of cholesteryl ester hydrolase, and rapid hydrolysis of cholesteryl esters. The newly released cholesterol is transported to the outer mitochondrial membrane, although the actual underlying mechanism is not defined. Based on the currently available information, it appears that transport of hydrophobic cholesterol from the aqueous environment to OMM is primarily facilitated by the non-vesicular cholesterol transport mechanism involving StarD proteins such as the StarD4 and StarD5 family, which avidly bind cholesterol. In addition, cytoskeletal components/structures, particularly vimentin intermediate filaments, and direct interaction of lipid droplets to cellular organelles (e.g., mitochondria) and other cytosolic factors, steroidogenesis activator polypeptide (SAP) and changes in cellular architecture could also contribute to cholesterol transport to OMM.

The next step in cholesterol transport to mitochondria is the transfer from the outer to the inner mitochondrial membrane; this is considered as a rate-limiting step in hormone-induced steroid formation. Two proteins, translocator protein (18 kDa, TSPO) and steroidogenic acute regulatory (StAR) protein, which presumably work in concert, mediate this transfer. TSPO, previously known as the peripheral-type benzodiazepine receptor, is a high-affinity drug- and cholesterol-binding mitochondrial protein. StAR is a hormone-induced mitochondriatargeted protein that has been shown to initiate cholesterol transfer into mitochondria. The current thinking is that functional cooperation between TSPO and proteins such as the cAMP-dependent protein kinase regulatory subunit $\alpha$ (PKA-RI $\alpha$ ) and the PKA-RI $\alpha$ - and TSPO-associated acyl-coenzyme A binding domain containing 3 (ACBD3) protein, PAP7, cholesterol is transferred to and docked at the OMM. The TSPO-dependent import of StAR into mitochondria, StAR interaction with VDAC1, and phosphate carrier protein (PCP) on the OMM, and the association of TSPO with the outer/inner mitochondrial membrane contact sites, drives the intramitochondrial cholesterol transfer and subsequent steroid formation.

\section{List of abbreviations used}

ACAT 1: acyl-coenzyme A:cholesterol acyltransferase 1; ACTH: adrenocorticotropin hormone; AII: angiotensin II; ANC: adenine nucleotide transporter; AALO: allopregnanolone; CEH: neutral cholesteryl ester hyrplase; CE: cholesteryl ester; CEs: cholesteryl esters; CLA-1: CD36 and LIMP-II analogues-1; CLMP: c-terminal linking and modulating protein; CLP36: $C$-terminal LIM domain protein 36; CRAC: domain; cholesterol recognition amino acid consensus domain; DHEA: dihydroepiandrosterone; DHT: dihydrotestosterone; DHEA: dehydroepiandrosterone; Dlg: the Drosophila discs large protein; ECD: extracellular domain; E3KARP: sodium hydrogen exchanger type 3 kinase A regulatory protein; EBP50: ERM binding protein 50; ER: endoplasmic reticulum; ERM: ezrin, the radixin and the moesin; FERM: Four-point one, ezrin, radixin and moesin; FRET: quantitative fluorescence resonance energy transfer; FSH: follicle-stimulating hormone; hCG: human chorionic gonadotropin; HDL: high-density lipoprotein; HSL: hormone-sensitive lipase; IF: vimentin-intermediate filaments; IMM: inner mitochondrial membrane; LDL: lowdensity lipoprotein; LH: Leuteinizing hormone; NHERF1: $\underline{\mathrm{Na}}+/ \underline{\mathrm{H}}+$ exchange regulatory factor; NHERF2: $\underline{\mathrm{Na}}+/ \underline{\mathrm{H}}+$ exchange regulatory factor 2 ; NPC1: NiemanPick type C1; NPC2: Nieman-Pick type C2; OMM: outer mitochondrial membrane; NSF: $N$-ethylmaleimide-sensi- 
tive factor; OMM: outer mitochondrial membrane; ORPs: OSBP-related proteins; OSBP: oxysterol-binding protein; CYP11A1: P450c11A; CYP11B1: P450c11; CYP11B2: aldosterone synthase; CYP17: P450c17; CYP21A2: P450c21; PBR: peripheral-type benzodiaz-

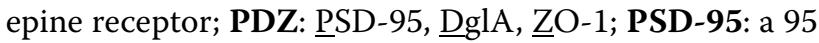
$\mathrm{kDa}$ protein involved in signaling in the post-synaptic density; PAP7: PKA regulatory subunit RI $\alpha$-associated protein; PKA: cAMP-dpendent protein kinase; POC: proopiomelanocortin; RGS12: regulator of G protein signaling 12; PRAX-1: TSPO-associated protein-1; RIL: reversion-induced LIM protein; SCAP: SREBP cleavageactivating protein; $\mathbf{S C P}_{2}$ : sterol career $\operatorname{protein}_{2} ; \boldsymbol{\alpha}$-SNAP: soluble NSF attachment protein; SNAP23: synaptosomal-associated protein of 23; SNAP25: synaptosomalassociated protein of 25; SNAREs: SNAP receptors; SRBI: Scavenger receptor Class B, type I; SREBP: sterol-regulatory element-binding proteins; StAR: steroidogenic acute regulatory protein; START domain: StAR-related lipid transfer domain; THDOC: allotetrahydrodeoxycortico; TSPO: translocator protein; VAMP4: vesicle-associated membrane protein4; VDAC: voltage-dependent anion channel; ZO1: the zonula occludens 1 protein involved in maintaining epithelial cell polarity;

\section{Competing interests}

The authors declare that they have no competing interests.

\section{Authors' contributions}

$J H, Z Z, W-J S$ and SA provided background material and unpublished data for this review. SA drafted the manuscript. JH and ZZ contributed equally to this review. All authors read and approved the final manuscript.

\section{Acknowledgements}

This work was supported by a grants from the Office of Research and Development, Medical Service, Department of Veterans Affairs and the National Institutes of Health (HL033881 and HL092473) (SA). The authors thank Mr. Kristopher Morrow for his assistance with the illustrations.

\section{Author Details}

1 Geriatric Research, Education and Clinical Center, VA Palo Alto Health Care System, Palo Alto, California 94304, USA, 2 Stanford University, Stanford, California 94305, USA and ${ }^{3}$ Norris Cotton Cancer Center, Dartmouth Medical School, 1 Medical Center Drive, Lebanon, NH 03756, USA

Received: 17 March 2010 Accepted: 1 June 2010

Published: 1 June 2010

\section{References}

1. Payne AH, Hales DB: Overview of steroidogenic enzymes in the pathway from cholesterol to active steroid hormones. Endocr Rev 2004, 25:947-970

2. Pikuleva IA: Cholesterol-metabolizing cytochromes P450. Drug Metab Dispos 2006, 34:513-520

3. Miller WL: Steroidogenic enzymes. Endocr Dev 2008, 13:1-18

4. Halkersten IDK, Eichorn J, Hechtor O: A requirement for reduced triphosphopyridine nucleotides for cholesterol side-chain cleavage by mitochondrial fractions of bovine adrenal cortex. J Biol Chem 1961, 236:374-380

5. Lambeth JD: Cytochrome P-450scc: a review of the specificity and properties of the cholesterol binding sites. Endocr Res 1986, 12:371-392.

6. Hall PF: Cytochromes P450 and the regulation of steroid synthesis. Steroids 1987, 48:131-196.
7. Miller WL: Molecular biology of steroid hormone synthesis. Endocr Rev 1988, 9:295-318.

8. Stocco DM, Clark BJ: Regulation of the acute production of steroids in steroidogenic cells. Endocr Rev 1996, 17:221-244.

9. Azhar S, Reaven E: Scavenger receptor class BI and selective cholesteryl ester uptake: partners in the regulation of steroidogenesis. Mol Cell Endocrinol 2002, 195:1-26.

10. Conley AJ, Mason J: Placental steroid hormones. Baillieres Clin Endocrinol Metab 1990, 4:249-272.

11. Strauss JF, Martinez F, Kiriakidou M: Placental steroid hormone synthesis: unique features and unanswered questions. Biol Reprod 1996, 54:303-311.

12. Mellon SH, Vaudry H: Biosynthesis of neurosteroids and regulation of their synthesis. Int Rev Neurobiol 2001, 46:33-78.

13. Tsutsui K: Minireview: progesterone biosynthesis and action in the developing neuron. Endocrinology 2008, 149:2757-2761

14. Rego Do JL, Seong JY, Burel D, Leprince J, Luu-The V, Tsutsui K, Tonon MC, Pelletier G, Vaudry H: Neurosteroid biosynthesis: enzymatic pathways and neuroendocrine regulation by neurotransmitters and neuropeptides. Front Neuroendocrinol 2009, 30:259-301.

15. Charreau EH, Calvo JC, Nozu K, Pignataro O, Catt KJ, Dufau ML: Hormonal modulation of 3-hydroxy-3-methylglutaryl coenzyme A reductase activity in gonadotropin-stimulated and desensitized testicular Leydig cells. J Biol Chem 1981, 256:12919-12724.

16. Azhar S, Chen YD, Reaven GM: Gonadotropin modulation of 3-hydroxy3-methylglutaryl coenzyme: A reductase activity in desensitized rat ovary. Biochemistry 1984, 23:4533-4538.

17. Golos TG, Strauss JF: 8-Bromoadenosine cyclic 3', 5'-phosphate rapidly increases 3-hydroxy-3-methylglutaryl Coenzyme A reductase mRNA in human granulosa cells: role of cellular sterol balance in controlling the response to tropic stimulation. Biochemistry 1988, 27:3503-3506.

18. Rainey WE, Shay JW, Mason Jl: ACTH induction of 3-hydroxy-3methylglutaryl coenzyme A reductase, cholesterol biosynthesis, and steroidogenesis in primary cultures of bovine adrenocortical cells. J Biol Chem 1986, 261:7322-7326.

19. Goldstein JL, Brown MS: The LDL receptor. Arterioscler Thromb Vasc Biol 2009, 29:431-438.

20. Azhar S, Leers-Sucheta S, Reaven E: Cholesterol uptake in adrenal and gonadal tissues: the SR-BI and 'selective' pathway connection. Front Biosc 2003:s998-1029.

21. Marsh JM: The role of cyclic AMP in gonadal arteroidogenesis. Bio/ Reprod 1976, 14:30-53.

22. Simpson ER, Waternan MR: Regulation by ACTH of steroid hormone biosynthesis in the adrenal cortex. Can J Biochem Cell Biol 1983, 61:692-707.

23. Sanorn BM, Heindel JJ, Robinson GA: The role of cyclic nucleotides in the reproductive processes. Ann Rev Physiol 1980, 42:37-57.

24. Waterman MR, Keeney DS: Signal transduction pathways combining peptide hormone and steroidogenesis. Vit Horm 1996, 52:129-148.

25. Strauss JF, Golos TG, Silavin SL, Soto EA, Takagi K: Involvement of cyclic AMP in the functions of granulosa and luteal cells: regulation of steroidogenesis. Prog Clin Biol Res 1988, 267:177-200.

26. Spat A, Hunyady L: Control of aldosterone secretion: a model for convergence in cellular signaling pathways. Physiol Rev 2004, 84:489-539.

27. Moyle WR, Kong YC, Ramachandran J: Steroidogenesis and cyclic adenosine 3',5'-monophosphate accumulation in rat adrenal cells: divergent effects of adrenocorticotropin and its o-nitrophenyl sulfenyl derivative. J Biol Chem 1973, 248:2409-2417.

28. Sala GB, Keiko H, Catt KJ, Dufau ML: Adrenocorticotropin actions in isolated adrenal cells: the intermediate role of cyclic AMP in stimulation of corticosterone synthesis. J Biol Chem 1979, 254:3861-3865.

29. Braley LM, Williams GH: Rat adrenal cell sensitivity to angiotensin II, $\mathbf{a}^{-1}$ 24-ACTH, and potassium: a comparative study. Am J Physiol 1977, 233:E402-E406.

30. Fujita K, Agilera G, Catt KJ: The role of cyclic AMP in aldosterone production by isolated zona glomerulosa cells. J Biol Chem 1979, 254:8567-8574.

31. Knecht M, Amsterdam A, Catt $K$ : The regulatory role of cyclic AMP in hormone-induced granulosa cell differentiation. J Biol Chem 1983, 256:10628-10633. 
32. Adashi EY, Resnick CE: Forskolin-induced differentiation of cultured rat granulosa cells: new evidence for an intermediary role of adenosine 3', 5 '-monophosphate in the mechanism action of follicle-stimulating hormone. Endocrinology 1984, 115:183-190.

33. Marsh JM, Butcher RW, Savard K, Sutherlad EW: The stimulatory effect of luteinizing hormone on adenosine 3', 5'-monophosphate accumulation in corpus luteum slices. J Biol Chem 1966, 241:5436-5440.

34. Sala GB, Dufau ML, Catt KJ: Gonadotropin action in isolated ovarian luteal cells: The intermediate role of adenosine 3': 5'-monophosphate in hormonal stimulation of progesterone synthesis. J Biol Chem 1979, 254:2077-2088

35. Magoffin DA: Evidence that luteinizing hormone-stimulated differentiation of purified ovarian theca-interstitial cells is mediated by both type I and type II adenosine 3', 5'-monophosphate-dependent protein kinases. Endocrinology 1989, 125:1464-1473.

36. Zachow RJ, Tash JS, Terranova PF: Tumor necrosis factor-alpha attenuation of luteinizing hormone-stimulated androstenedione production by ovarian theca-interstitial cells: inhibition of loci with the adenosine 3', 5'-monophosphate-dependent signaling pathway. Endocrinology 1993, 133:2269-2276.

37. Moyle WR, Ramachandran J: Effect of LH on steroidogenesis and cAMP accumulation in rat Leydig cell preparations and mouse tumor Leydig cells. Endocrinology 1973, 127:127-134.

38. Mendelson C, Dufau M, Catt K: Gonadotropin binding and stimulation of cyclic adenosine 3', 5'-monophosphate and testosterone production in isolated Leydig cells. J Biol Chem 1975, 250:8818-8823.

39. McKenna TJ, Fearon U, Clarke D, Cunningham SK: A critical review of the origin and control of adrenal androgens. Baillieres Clin Obstet Gynecol 1997, 11:229-248.

40. Miller WL: Androgen biosynthesis from cholesterol to DHEA. Mol Cell Endocrinol 2002, 198:7-14.

41. Simpson ER, Waterman MR: Regulation of the synthesis of steroidogenic enzymes in adrenal cortical cells by ACTH. Annu Rev Physio/ 1988, 50:427-470

42. Moore CC, Miller WL: The role of transcriptional regulation in steroid hormone biosynthesis. J Steroid Biochem Mol Biol 1991, 40:517-525.

43. Lauber ME, Kagawa N, Waterman MR, Simpson ER: CAMP-dependent and tissue-specific expression of genes encoding steroidogenic enzymes in bovine luteal and granulosa cells in primary culture. Mol Cell Endocrinol 1993, 93:227-233.

44. Parker KL, Scimmer BP: Transcriptional regulation of the genes encoding P-450 steroid hydroxylases. Vit Horm 1995, 51:339-370.

45. Payne $A H$, Youngblood $G L$ : Regulation of expression of steroidogenic enzymes in Leydig cells. Biol Reprod 1995, 52:217-225.

46. Davis WW, Garren LD: On the mechanism of action of adrenocorticotropic hormone: the inhibitory site of cycloheximide in the pathway of steroid biosynthesis. J Biol Chem 1968, 243:5153-5157.

47. Simpson ER, McCarthy JL, Peterson JA: Evidence that the cycloheximidesensitive site of adrenocorticotropic hormone action is in the mitochondrion: changes in pregnenolone formation, cholesterol content, and electron paramagnetic resonance spectra of cytochrome P-450. J Biol Chem 1978, 253:3135-3139.

48. Toaff ME, Strauss JF, Flickinger GL, Shattil SJ: Relationship of cholesterol supply to mitochondrial steroid synthesis. J Biol Chem 1979, 254:3977-3982.

49. Mori M, Marsh JM: The site of luteinizing hormone stimulation of steroidogenesis in mitochondria of the rat corpus luteum. $J$ Biol Chem 1982, 257:6178-6183.

50. Privalle $C T$, Crivello JF, Jefcoate CR: Regulation of intramitochondrial cholesterol transfer to side-chain cleavage cytochrome P-450 in rat adrenal gland. Proc Natl Acad Sci USA 1983, 80:702-706.

51. Sanderson JT: The steroid hormone biosynthesis pathway as a target for endocrine-disrupting chemicals. Toxicol Sci 2006, 94:3-21.

52. Espenshade PJ, Hughes AL: Regulation of sterol synthesis in eukaryotes. Annu Rev Genet 2007, 41:401-427.

53. Brown MS, Goldstein JL: Cholesterol feedback: from Schoenheimer's bottle to Scap's MELADAL. J Lipid Res 2009, 50:S15-S27.

54. Liscum, Munn NJ: Intracellular cholesterol transport. Biochim Biophys Acta 1999, 1438:19-37.

55. Soccio RE, Breslow JL: Intracellular cholesterol transport. Arterioscler Thromb Vasc Biol 2004, 24:1150-1160.
56. Ikonen E: Cellular cholesterol trafficking and compartmentalization. Nat Rev Mol Cell Biol 2008, 9:125-138

57. Mesmin B, Maxfield FR: Intracellular sterol dynamics. Biochim Biophys Acta 2009, 179(1):636-645

58. Urbani L, Simoni RD: Cholesterol and vesicular stomatitis virus $G$ protein take separate routes from the endoplasmic reticulum to the plasma membrane. J Biol Chem 1990, 265:1919-1923.

59. Heino S, Lusa S, Somerharju P, Ehnholm C, Olmkonen VM, Ikonen E: Dissecting the role of the Golgi complex and the lipid rafts in biosynthetic transport of cholesterol to the cell surface. Proc Natl Acad Sci USA 2000, 97:8375-8380.

60. Smart EJ, Ying Y, Donzell WC, Anderson RG: A role for caveolin in transport of cholesterol from endoplasmic reticulum to plasma membrane. J Biol Chem 1996, 271:29427-29435.

61. Uittenbogaard A, Ying Y, Smart EJ: Characterization of a cytosolic heatshock protein-caveolin chaperone complex. Involvement in cholesterol trafficking. J Biol Chem 1998, 273:6525-6532.

62. Hynynen R, Laitinen S, Tanhuanpää K, Lusa S, Ehnholm C, Somerharju P, Ikonen E, Olkkonen VM: Overexpression of OSBP-related protein 2 (ORP2) induces changes in cellular cholesterol metabolism and enhances endocytosis. Biochem J 2005, 390:273-283.

63. Puglielli L, Rigotti A, Greco AV, Santos MJ, Nervi F: Sterol carrier protein-2 is involved in cholesterol transfer from the endoplasmic reticulum to the plasma membrane in human fibroblasts. J Biol Chem 1995, 270:18723-18726

64. Baum CL, Reschly EJ, Gayen AK, Groh ME, Schadick K: Steror carrier protein-2 overexpression enhances sterol cycling and inhibits cholesterol ester synthesis and high density lipoprotein cholesterol secretion. J Biol Chem 1997, 272:6490-6498.

65. Liscum L, Ruggiero RM, Faust JR: The intracellular transport of low density lipoprotein-derived cholesterol is defective in Nieman-Pick type C fibroblasts. J Cell Biol 1989, 108:1625-1635.

66. Chang T-Y, Chang CCY, Ohgami N, Yamauchi Y: Cholesterol sensing, trafficking, and esterification. Annu Rev Cell Dev Biol 2006, 22:129-157.

67. Buhman KK, Chen HC, Farese RV Jr: The enzymes of neutral lipid synthesis. J Biol Chem 2001, 276:40369-40372.

68. Chang T-Y, Li B-L, Chang CCY, Urano Y: Acyl-coenzyme A:cholesterol acyltransferases. Am J Physiol Endocrinol Metab 2009, 297:E1-E9.

69. Goodman JM: The gregarious lipid droplet. J Biol Chem 2008, 283:28005-28099

70. Ohsaki Y, Cheng J, Suzuki M, Shinohara Y, Fujita A, Fujimoto T: Biogenesis of cytoplasmic lipid droplets: From the lipid ester globule in the membrane to the visible structure. Biochim Biophys Acta 2009, 1791:399-407.

71. Olofsson S-O, Boström P, Andersson L, Rutberg M, Perman J, Borén J: Lipid droplets as dynamic organelles connecting storage and efflux of lipids. Biochim Biophys Acta 2009, 1791:448-458.

72. Reaven E, Tsai L, Azhar S: Cholesterol uptake by the 'selective' pathway of ovarian granulosa cells: early intracellular events. J Lipid Res 1995, 36:1602-1617.

73. Reaven E, Tsai L, Azhar S: Intracellular events in the "selective" transport of lipoprotein-derived cholesteryl esters. J Biol Chem 1996, 271:16208-16217.

74. Azhar S, Nomoto A, Leers-Sucheta S, Reaven E: Simultaneous induction of an $\mathrm{HDL}$ receptor protein (SR-BI) in a physiologically relevant steroidogenic cell model. J Lipid Res 1998, 39:1616-1628.

75. Reaven E, Leers-Sucheta S, Nomoto A, Azhar S: Expression and microvillar localization of scavenger receptor class B, type I (SR-BI) and selective cholesteryl ester uptake in Leydig cells from rat testis. J Lipid Res 2000, 41:343-356.

76. Guraya SS: Histochemical observations on the lipid changes in the ovarian interstitial gland tissues of rats. J Reprod Fert 1975, 45:141-145.

77. Zoller LC, Malamed S: Acute effects of ACTH on dissociated adrenocortical cells: quantitative changes in mitochondria and lipid droplets. Anat Rec 1975, 182:473-478.

78. Mendis-Handagama SM: Luteinizing hormone on Leydig cell structure and function. Histol Histopathol 1997, 12:869-892.

79. Pedersen RC: Cholesterol biosynthesis, storage and mobilization in steroidogenic organs. In Biology of Cholesterol Edited by: Yeagle PL. CRC Press, Inc, Boca Roton, FL; 1988:39-69. 
80. Behrman HR, Armstrong DT: Cholesterol esterase stimulation by luteinizing hormone in luteinized rat ovaries. Endocrinology 1969, 85:474-480

81. Behrman HR, Greep RO: Hormonal dependence of cholesterol ester hydrolase in the corpus luteum and adrenal. Horm Metab Res 1972, 4:206-209.

82. Sugii S, Reid PC, Ohgami N, Du H, Chang TY: Distinct endosomal compartments in early trafficking of low density lipoprotein-derived cholesterol. J Biol Chem 2003, 278:27180-27189.

83. Wojtanik KM, Liscum L: The transport of LDL-derived cholesterol to the plasma membrane is defective in NPC1 cells. J Bio/ Chem 2003, 278:14850-14856.

84. Miller WL: Steroidogenic acute regulatory protein (StAR), a novel mitochondrial cholesterol transporter. Biochim Biophys Acta 2007, 1771:663-676.

85. Stocco DM: Intramitochondrial cholesterol transfer. Biochim Biophys Acta 2000, 1486:184-197.

86. Ioannou YA: The structure and function of the Niemann-Pick C1 protein. Mol Genet Metab 2000, 71:175-81.

87. Garver WS, Heidenreich RA: The Niemann-Pick C proteins and trafficking of cholesterol through the late endosomal/lysosomal system. Curr Mol Med 2002, 2:485-505.

88. Infante RE, Wang ML, Radhakrishnan A, Kwon HJ, Brown MS, Goldstein JL: NPC2 facilitates bidirectional transfer of cholesterol between NPC1 and lipid bilayers, a step in cholesterol egress from lysosomes. Proc Natl Acad Sci USA 2008, 105:15287-15292.

89. Storch J, Xu Z: Nieman-Pick C2 (NPC2) and intracellular cholesterol trafficking. Biochim Biophys Acta 2009, 1791:671-678.

90. Watari H, Blanchette-Mackie EJ, Dwyer NK, Sun G, Glick JM, Patel S, Neufled EB, Pentchev G, Strauss JF: NPC1-containing compartment of human granulosa-luteal cells: a role in the intracellular trafficking of cholesterol supporting steroidogenesis. Exp Cell Res 3rd edition. 2000, 255:56-66.

91. Xie C, Richardson JA, Turley SD, Dietschy JM: Cholesterol substrate pools and steroid hormone levels are normal in the face of mutational inactivation of NPC1 protein. J Lipid Res 2006, 47:953-963.

92. Zhang M, Liu P, Dwyer NK, Christenson LK, Fujimoto T, Martinex F, Comly M, Hanover JA, Balnchette-mackie EJ, Strauss JF: MLN64 mediates mobilization of lysosomal cholesterol to steroidogenic mitochondria. J Biol Chem 2009, 277:33300-33310.

93. Charman M, Kennedy BE, Osborne N, Karten B: MLN64 mediates egress of cholesterol from endosomes to mitochondria in the absence of functional Niemann-Pick Type C1 protein. J Lipid Res 2010, 51:1023-1034

94. Alpy F, Stoeckler ME, Dierich A, Escola JM, Wendling C, Chenard MP, Vanier MT, Gruenberg J, Tomasetto C, Rio MC: The steroidogenic acute regulatory protein homolog MLN64, a late endosomal cholesterolbinding protein. J Bio/ Chem 2001, 276:4261-4269.

95. Kishida T, Kostetskii I, Zhang Z, et al.: Targeted mutation of the MLN64 START domain causes only modest alterations in cellular sterol metabolism. J Biol Chem 2004, 279:19276-19285.

96. Choudhury A, Dominguez M, Puri V, Shram DK, Narita K, Wheatley CL, Marks DL, Pagono RE: Rab proteins mediate Golgi transport of caveolainternalized glycosphingolipids and correct lipid trafficking in NiemanPick C cells. J Clin Invest 2002, 109:1541-1550.

97. Walter M, Davies JP, Ioannou YA: Telomerase immortalization upregulates Rab9 expression and restores LDL cholesterol egress from Nieman-Pick C1 late endosomes. J Lipid Res 2003, 44:243-253.

98. Glass C, Pittman RC, Weinstein DB, Steinberg D: Dissociation of tissue uptake of cholesterol ester from that of apoprotein A-I of rat plasma high density lipoprotein: selective delivery of cholesterol ester to liver, adrenal, and gonad. Proc Natl Acad Sci USA 1983, 80:5435-5439.

99. Reaven E, Chen YD, Spicher M, Azhar S: Morphological evidence that high density lipoproteins are not internalized by steroid-producing cells during in situ organ perfusion. J Clin Invest 1984, 74:1384-1397.

100. Reaven E, Chen YD, Spicher M, Hwang SF, Mondon CE, Azhar S: Uptake of low density lipoproteins by rat tissues. Special emphasis on the luteinized ovary. J Clin Invest 1986, 77:1971-1984.

101. Azhar S, Stewart D, Reaven E: Utilization of cholesterol-rich lipoproteins by perfused rat adrenals. J Lipid Res 1989, 30:1799-1810.
102. Azhar S, Tsai L, Reaven E: Uptake and utilization of lipoprotein cholesterol esters by rat granulosa cells. Biochim Biophys Acta 1990, 1047:148-160.

103. Pittman RC, Knecht TP, Rosenbaum MS, Taylor CA Jr: A nonendocytotic mechanism for the selective uptake of high density lipoproteinassociated cholesterol esters. J Biol Chem 1987, 262:2443-24450.

104. Acton S, Rigotti A, Landschulz KT, Xu S, Hobbs HH, Krieger M: Identification of scavenger receptor SR-BI as a high density lipoprotein receptor. Science 1996, 271:518-520.

105. Rigotti A, Miettinen HE, Krieger M: The role of the high-density lipoprotein receptor SR-BI in the lipid metabolism of endocrine and other tissuse. Endocr Rev 2003, 24:357-387.

106. Landschulz KT, Pathak RK, Rigotti A, Krieger M, Hobbs HH: Regulation of scavenger receptor, class $B$, type I, high density lipoprotein receptor, in liver and steroidogenic tissues of the rat. J Clin Invest 1996, 98:984-995.

107. Garaf GA, Roswell KL, Smart EJ: 17p-Estradiol promotes the upregulation of SR-BII in HepG2 cells and rat liver. J Lipid Res 2001, 42:1444-1449.

108. Rigotti A, Edelman ER, Seifert P, labal SN, DeMattos RB, Temel RE, Krieger $M$, Williams DL: Regulation by adrenocorticotropic hormone of the in vivo expression of scavenger receptor class B type I (SR-BI), a high density lipoprotein receptor, in steroidogenic cells of the murine adrenal gland. J Biol Chem 1996, 271:33545-33549.

109. Azhar S, Nomoto E, Reaven E: Hormonal regulation of adrenal microvillar channel formation. J Lipid Res 2002, 43:861-871.

110. Reaven E, Nomoto A, Leers-Sucheta S, Temel R, Williams DL, Azhar S: Expression and microvillar localization of scavenger receptor, class $\mathrm{B}$, type I (a high density lipoprotein receptor) in luteinized and hormonedesensitized rat ovarian models. Endocrinology 1998, 139:2847-2856.

111. Reaven E, Boyles J, Spicher M, Azhar S: Evidence for surface entrapment of cholesterol-rich lipoproteins in luteinized ovary. Arteriosclerosis 1988, 8:298-309.

112. Reaven E, Spicher M, Azhar S: Microvillar channels: a unique plasma membrane compartment for concentrating lipoproteins on the surface of rat adrenal cortical cells. J Lipid Res 1989, 30:1551-60.

113. Reaven $E$, Shi XY, Azhar S: Interaction of lipoproteins with isolated ovary plasma membranes. J Biol Chem 1990, 265:19100-19111.

114. Reaven E, Leers-Sucheta S, Nomoto A, Azhar S: Expression of scavenger receptor class B type I (SR-BI) promotes microvillar channel formation and selective cholesteryl ester transport in a heterologous reconstituted system. Proc Natl Acad Sci USA 2001, 98:1613-1618.

115. Peng Y, Akmentin W, Connelly MA, Lund-Katz S, Phillips MC, Williams DL: Scavenger receptor $\mathrm{BI}(\mathrm{SR}-\mathrm{BI})$ clustered on microvillar extensions suggests that this plasma membrane domain is a way station for cholesterol trafficking between cells and high-density lipoprotein. $\mathrm{Mol}$ Biol Cell 2004, 15:384-396.

116. Reaven E, Cortez Y, Leers-Schuta S, Nomoto A, Azhar S: Dimerization of the scavenger receptor class $B$ type I: formation, function, and localization in diverse cells and tissues. J Lipid Res 2004, 45:513-528.

117. Reaven E, Nomoto A, Cortez Y, Azhar S: Consequences of overexpression of rat Scavenger Receptor, SR-BI, in an adrenal model. Nutr Metab (Lond) 2006, 3:43

118. Williams DL, Wong JS, Hamilton RL: SR-BI is required for microvillar channel formation and the localization of HDL particles to the surface of adrenocortical cells in vivo. J Lipid Res 2002, 43:544-549.

119. Babitt J, Trigatti B, Rigotti A, Smart EJ, Anderson RGW, Xu S, Krieger M: Murine SR-BI, a high density lipoprotein receptor which mediates selective lipid uptake, is $\mathrm{N}$-glycosylated, fatty acylated, and resides in plasma caveolae. J Biol Chem 1997, 272:13242-13249.

120. Graf GA, Connell PM, van der Westhuyzen DR, Smart EJ: SR-BI promotes the selective uptake of HDL cholesterol ethers into caveolae. J Biol Chem 1999, 274:12043-12048.

121. Rhainds D, Bourgeois P, Bourret G, Huard K, Falstrault L, Brissette L: Localization and regulation of SR-BI in membrane rafts of HepG2 cells. J Cell Sci 2004, 117:3095-3105.

122. Matveev S, van der Westhuyzen DR, Smart EJ: Co-expression of scavenger receptor-BI and caveolin -1 is associated with enhanced selective cholesteryl ester uptake in THP-1 macrophages. J Lipid Res 1999, 40:1647-1654

123. Matveev S, Uittenbogaard A, van der Westhuyzen D, Smart EJ: Caveolin-1 negatively regulates SR-BI mediated selective uptake of high-density lipoprotein-derived cholesteryl ester. Eur J Biochem 2001, 268:5609-5616. 
124. Wang L, Connelly MA, Ostermeyer AG, Chen HH, Williams DL, Brown DA: Caveolin-1 does not affect SR-BI-mediated cholesterol efflux or selective uptake of cholesteryl ester in two cell lines. J Lipid Res 2003, 44:807-815.

125. Calvo D, Gómez-Coronado D, Lasunción MA, Vega MA: CLA-1 is an 85-kD plasma membrane glycoprotein that acts as a high-affinity receptor for both native (HDL, LDL, and VLDL) and modified (OxLDL and AcLDL) lipoproteins. Arterioscler Thromb Vasc Biol 1997, 17:2341-2349.

126. Xu S, Laccotripe M, Huang X, Rigotti A, Zannis VI, Krieger M: Apolipoproteins of HDL can directly mediate binding to the scavenger receptor SR-BI, an HDL receptor that mediates selective lipid uptake. J Lipid Res 1997, 38:1289-1298.

127. Wang N, Weng W, Breslow JL, Tall AR: Scavenger receptor BI (SR-BI) is upregulated in adrenal gland in apolipoprotein $A-I$ and hepatic lipase knock-out mice as a response to depletion of cholesterol stores. In vivo evidence that $\mathrm{SR}-\mathrm{BI}$ is a functional high density lipoprotein receptor under feedback control. J Biol Chem 1996, 271:21001-21004.

128. Rigotti A, Trigatti BL, Penman M, Rayburn H, Herz J, Krieger M: A targeted mutation in the murine gene encoding the high density lipoprotein $(\mathrm{HDL})$ receptor scavenger receptor class $B$ type I reveals its key role in HDL metabolism. Proc Natl Acad Sci USA 1997, 94:12610-12615.

129. Varban ML, Rinninger F, Wang N, Fairchild-Huntress V, Dunmore JH, Fang Q, Gosselin ML, Dixon KL, Deed JD, Acton SL, Tall AR, Huszar D: Targeted mutation reveals a central role for SR-BI in hepatic selective uptake of high density lipoprotein cholesterol. Proc Natl Acad Sci USA 1998, 95:4619-4624.

130. Viñals M, Xu S, Vasile E, Krieger M: Identification of the $\mathrm{N}$-linked glycosylation sites on the high density lipoprotein (HDL) receptor SR-BI and assessment of their effects on HDL binding and selective lipid uptake. J Biol Chem 2003, 278:5325-5332.

131. Gu X, Trigatti B, Xu S, Acton S, Babitt J, Krieger M: The efficient cellular uptake of high density lipoprotein lipids via scavenger receptor class $B$ type I requires not only receptor-mediated surface binding but also receptor-specific lipid transfer mediated by its extracellular domain. J Biol Chem 1998, 273:26338-26348.

132. Connelly MA, Klein SM, Azhar S, Abumrad NA, Williams DL: Comparison of class B scavenger receptors, CD36 and scavenger receptor BI (SR-BI), shows that both receptors mediate high density lipoproteincholesteryl ester selective uptake but SR-BI exhibits a unique enhancement of cholesteryl ester uptake. J Biol Chem 1999, 274:41-47.

133. Parathath S, Sahoo D, Darlington YF, Peng Y, Collins HL, Rothblat GH, Williams DL, Connelly MA: Glycine 420 near the $C$-terminal transmembrane domain of SR-BI is critical for proper delivery and metabolism of high density lipoprotein cholesteryl ester. J Bio/ Chem 2004, 279:24976-24985.

134. Rodrigueza WV, Thuahnai ST, Temel RE, Lund-Katz S, Phillips MC, Williams DL: Mechanism of scavenger receptor class B type I-mediated selective uptake of cholesteryl esters from high density lipoprotein to adrenal cells. J Biol Chem 1999, 274:20344-20350.

135. Ikemoto M, Arai H, Feng D, Tanaka K, Aoki J, Dohmae N, Takio K, Adachi H, Tsujimoto M, Inoue K: Identification of a PDZ-domain-containing protein that interacts with the scavenger receptor class B, type I. Proc Natl Acad Sci USA 2000, 97:6538-6543.

136. Silver DL: A carboxyl-terminal PDZ-interacting domain of scavenger receptor $B$, type $I$ is essential for cell surface expression in liver. $J$ Biol Chem 2002, 277:34042-34047.

137. Siver DL, Wang N, Vogel S: Identification of a small PDZK1-associated protein, DD96/MAP17, as a regulator of PDZK1 and plasma high density lipoprotein levels. J Biol Chem 2003, 278:28528-28532.

138. Kocher O, Yesilaltay A, Cirovic C, Pal R, Rigotti A, Krieger M: Targeted disruption of the PDZK1 gene in mice causes tissue-specific depletion of the high density lipoprotein receptor scavenger receptor class $B$, type I and altered lipoprotein metabolism. J Biol Chem 2003, 278:52820-52825.

139. Robichaud JC, Francis GA, Vance DE: A role for hepatic scavenger receptor class $B$, type I in decreasing high density lipoprotein levels in mice that lack phosphatidylethanolamine $\mathrm{N}$-methyltransferase. J Biol Chem 2008, 283:35496-354506.

140. Subbaiah PV, Gesquiere LR, Wang K: Regulation of the selective uptake of cholesteryl esters from high density lipoproteins by sphingomyelin. J Lipid Res 2005, 46:2699-2705.
141. Kocher O, Krieger M: Role of the adaptor protein PDZK1 in controlling the HDL receptor SR-BI. Curr Opin Lipido/ 2009, 20:234-241.

142. Zhu W, Saddar S, Seetharam D, Chambliss KL, Longoria C, Silver DL, Yuhanna IS, Shaul PW, Mineo C: The scavenger receptor class B type I adaptor protein PDZK1 maintains endothelial monolayer integrity. Circ Res 2008, 102:480-487.

143. Kellner-Weibel G, de la Llera-Moya M, Connelley MA, Stoudt G, Christian AE, Haynes MP, Williams DL, Rothblat GH: Expression of scavenger receptor $\mathrm{BI}$ in COS-7 cells alters cholesterol content and distribution. Biochemistry 2000, 39:221-229.

144. Parathath S, Connelly MA, Rieger RA, Rieger RA, Klein SM, Abumrad NA, De La Llera-Moya M, Iden CR, Rothblat GH, Williams DL: Changes in plasma membrane properties and phosphatidylcholine subspecies of insect Sf9 cells due to expression of scavenger receptor class B, type I, and CD36. J Biol Chem 2004, 279:41310-41318.

145. Chen W, Siver DL, Smith JD, Tall AR: Scavenger receptor-BI inhibits ATPbinding cassette transporter-mediated cholesterol efflux in macrophages. J Biol Chem 2000, 275:30794-30800.

146. Fanning AS, Anderson JM: PDZ domains: fundamental building blocks in the organization of protein complexes at plasma membrane. $J$ Clin Invest 1999, 103:767-772.

147. Harris BZ, Lim WA: Mechanism and role of PDZ domains in signaling complex assembly. J Cell Sci 2001, 114:3219-3231.

148. Sheng M, Sala C: PDZ domains and the organization of supermolecular complexes. Annu Rev Neurosci 2001, 24:1-29.

149. Van Ham M, Hendriks W: PDZ domains - glue and guide. Mol Biol Rep 2003, 30:69-82.

150. Nourry C, Grant SGN, Borg J-P: PDZ domain protein: plug and play. SCi STKE 2003 2003:RE7.

151. Huang AY, Sheng M: PDZ domains: structural modules for protein complex assembly. J Biol Chem 2002, 277:5699-5702.

152. Fan J-S, Zhang M: Signaling complex organization by PDZ domain proteins. Neurosignals 2002, 11:315-321.

153. Donowitz M, Cha B, Zachos NC, Brett CL, Sharma A, Tse CM, Li X: NHERF family and $\mathrm{NH} 3$ regulation. $J$ Physio/ 2005, 567:3-11.

154. Thelin WR, Hodson CA, Milgram SL: Beyond the brush border: NHERF4 blazes new NHERF turf. J Physio/ 2005, 567:13-19.

155. Yesilaltay A, Kocher O, Pal R, Leiva A, Quiñones V, Rigotti A, Krieger M PDZK1 is required for maintaining hepatic scavenger receptor, class $B$, type I (SR-BI) steady state levels but not its surface localization or function. J Biol Chem 2006, 281:28975-28980.

156. Fenske SA, Yesilaltay A, Pal R, Daniels K, Rigotti A, Krieger M, Kocher O: Overexpression of the PDZ1 domain of PDZK1 blocks the activity of hepatic scavenger receptor, class $B$, type I by altering its abundance and cellular localization. J Biol Chem 2008, 283:22097-22104.

157. Nakamura T, Shibata N, Nishimoto-Shiba T, Feng D, Ikemoto M, Motojima K, Iso-o N, Tsukamoto K, Tsujimoto M, Arai H: Regulation of SR-BI protein levels by phosphorylation of its associated protein, PDZK1. Proc Natl Acad Sci USA 2005, 102:13404-13409.

158. Feneske SA, Yesilaltay A, Pal R, Daniels K, Baker C, Quiñones V, Rigotti A, Krieger $M$, Kocher $O$ : Normal hepatic cell surface localization of the high density lipoprotein receptor, scavenger class B, type I depends on all four PDZ domains of PDZK1. J Biol Chem 2009, 284:5797-5806.

159. Komori H, Arai H, Kashima T, Huby T, Kita T, Ueda Y: Coexpression of CLA1 and human PDZK1 in murine liver modulates HDL cholesterol metabolism. Arterioscler Thromb Vasc Biol 2008, 28:1298-303.

160. Snow BE, Antonio L, Suggs S, Gutstein HB, Siderovski DP: Molecular cloning and expression analysis of rat Rgs12 and Rgs14. Biochem Biophys Res Commun 1997, 233:770-777.

161. Chatterjee TK, Fisher RA: Novel alternative splicing and nuclear localization of human RGS12 gene products. J Biol Chem 2000, 275:29660-29671.

162. Snow BE, Brothers GM, Siderovski DP: Molecular cloning of regulators of G-protein signaling family members and characterization of binding specificity of RGS12 PDZ domain. Methods Enzymol 2002, 344:740-761.

163. Wang H, Harrison-Shostak DC, Lemasters JJ: Herman B. Cloning of a rat CDNA encoding a novel LIM domain protein with homology to rat RIL. Gene 1995, 165:267-271.

164. Bauer K, Kratzer M, Otte M, et al:: Human CLP36, a PDZ-domain and LIMdomain protein, binds to a-actin- 1 and associates with actin filaments and stress fibers in activated platelets and endothelial cells. Blood 2000, 96:4236-4245 
165. Vallenius T, Luukko K, Mäkelä TP: CLP-36 PDZ-LIM protein associates with nonmuscle a actin-1 and a-actin-4. J Biol Chem 2000, 275:11100-11105.

166. Kiess M, Scharm B, Aguzzia A, Hajnal A, Klemenz R, Schwarte-Waldhoff I, Schäfer R: Expression of ril, a novel LIM domain gene, is downregulated in Hras-transformed cells and restored in phenotypic revertants. Oncogene 1995, 10:61-68.

167. Vallenius T, Scharm B, Vesikansa A, Luukko K, Schäfer R, Mäkelä TP: The PDZ-LIM protein RIL modulates actin stress fiber turnover and enhances the association of a-actin with F-actin. Exp Cell Res 2004 293:117-128.

168. Cho KO, Hunt CA, Kennedy MB: The rat brain postsynaptic density fraction contains a homolog of Drosophila discs-large tumor suppressed protein. Neuron 1992, 9:929-942.

169. Kistner U, Wenzel BM, Cases-Langhoff C, et al:: SAP90, a rat presynaptic protein related to the product of the Drosophila tumor suppressor gene dlgA. J Biol Chem 1993, 268:4580-4583.

170. Stathakis DG, Hoover KB, You Z, Bryant PJ: Human postsynaptic density95 (PSD95): location of the gene (DLG4) and possible function in nonneural as well as in neural tissues. Genomics 1997, 44:71-82.

171. Okamoto M, Sudhof TC: Mint 3: a ubiquitous mint isoform that does not bind to munc18-1 or -2. Eur J Cell Biol 1998, 77:161-165.

172. Shrivastava-Ranjan P, Faundez V, Fang G, Rees H, Lah JJ, Levey AL, Kahn RA: Mint $3 / \mathrm{X} 11 \gamma$ is an ADP-ribosylation factor-dependent adaptor that regulates the traffic of the Alzheimer's precursor protein from the trans-Golgi network. Mol Biol Cell 2008, 19:51-64.

173. Chikumi H, Barac A, Behbahani B, Gao Y, Teramoto H, Zheng Y, Gutkind JS: Homo- and hetero-oligomerization of PDZ-RhoGEF, LARG and p115RhoGEF by their C-terminal region regulates their in vivo RhoGEF activity and transforming potential. Oncogene 2004, 23:233-240.

174. Banerjee J, Wedegaertner PB: Identification of a novel sequence in PDZRhoGEF that mediates interaction with the actin cytoskeleton. Mol Biol Cell 2004, 15:1760-1775.

175. Mamathambika BS, Bardwell JC: Disulfide-linked protein folding pathways. Annu Rev Cell Dev Biol 2008, 24:211-235.

176. Trivedi MV, Laurence JS, Siahann TJ: The role of thiols and disulphides on protein stability. Curr Protein Pept Sci 2009, 10:614-625.

177. Stitham J, Gleim SR, Douville K, Arehart E, Hwa J: Versality and differential roles of cysteine residues in human prostacyclin receptor structure and function. J Biol Chem 2006, 281:37227-37236.

178. Gilbert HF: Molecular and cellular aspects of thiol-disulfide exchange. Adv Enzymol Relat Areas Mol Biol 1990, 63:69-172.

179. Nagahara N, Matsumura T, Okamoto R, Kajihara Y: Protein cysteine modifications: (1) medical chemistry for proteomics. Curr Med Chem 2009, 16:4419-4444

180. Silver DL, Wang N, Xiao X, Tall AR: High density lipoprotein (HDL) particle uptake mediated by scavenger receptor class $B$ type 1 results in selective sorting of $\mathrm{HDL}$ cholesterol from protein and polarized cholesterol secretion. J Biol Chem 2001, 276:25287-25293.

181. Pagler TA, Rhode S, Neuhofer RS, Laggner H, Strobl W, Hinterndorfer C, Volf I, Pavelka M, Eckhardt ER, van der Westhhuyzen DR, Schütz GJ, Stangl H: SR-BI-mediated high-density lipoprotein (HDL) endocytosis leads to HDL resecretion facilitating cholesterol efflux. J Biol Chem 2006, 281:11193-11204

182. Sun B, Eckhardt ER, Shetty S, van der Westhuyzen DR, Webb NR: Quantitative analysis of SR-BI-dependent HDL reteroendocytosis in hepatocytes and fibroblasts. J Lipid Res 2006, 47:1700-1713.

183. Pagler TA, Neuhofer A, Laggner H, Strobel W, Stang H: Cholesterol efflux via $\mathrm{HDL}$ resecretion occurs when cholesterol transport out of the lysosome is impaired. J Lipid Res 2007, 48:2141-2150

184. Daniels TR, Delgado T, Rodriguez JA, Helguera G, Penichet ML: The transferrin receptor part I: biology and targeting with cytotoxic antibodies for the treatment of cancer. Clin Immunol 2006, 121:144-158.

185. Liu PT, Heiskala M, Peterson PA, Yang Y: The roles of iron in health and disease. Mol Asp Med 2001, 22:1-87.

186. Nieland TJ, Ehrlich M, Krieger M, Kirchhausen T: Endocytosis is not required for the selective lipid uptake mediated by murine SR-BI. Biochim Biophys Acta 2005, 1734:44-51.

187. Lorenzi I, von Eckardstein A, Cavelier C, Rodosavljevic S, Rohrer L: Apolipoprotein A-I but not high-density lipoproteins are internalized by RAW macrophages: roles of ATP-binding cassette transporter A1 and scavenger receptor BI. J Mol Med 2008, 86:171-183.
188. Rosenfeld ME, Bowen-Pope DF, Ross R: Platelet-derived growth factor: morphologic and biochemical studies of binding, internalization and degradation. J Cell Physiol 1984, 121:263-274.

189. Synnes M, Prydz K, Lødal T, Brech A, Berg T: Fluid phase endocytosis and galactosyl receptor-mediated endocytosis employ different endosomes. Biochim Biophys Acta 1999, 1421:317-328.

190. Richardson DR, Baker E: Two saturable mechanisms of iron uptake from transferrin in human melanoma cells: the effect of transferrin concentration, chelators, and metabolic probes on transferrin and iron uptake. J Cell Physiol 1994, 161:160-168.

191. Finger EC, Lee Ny, You HJ, Blobe GC: Endocytosis of the type III transforming growth factor- $\beta$ (TGF $\beta$ ) receptor through the clathrinindependent/lipid raft pathway regulates TGF- $\beta$ signaling and receptor down regulation. J Biol Chem 2008, 283:34808-34818.

192. Uittenbogaard A, Everson WV, Matveev SV, Smart EJ: Cholesteryl ester is transported from caveolae to internal membrane as a part of a caveolin-annexin II lipid-protein. J Biol Chem 2002, 277:4925-4931

193. Kurzchalia TV, Dupree P, Parton RG, Kellner R, Virta H, Lehnert M, Simons K. VIP21, a 21-kD membrane protein is an integral component of transGolgi-network-derived transport vesicles. J Cell Biol 1992, 118:1003-1014

194. Smart EJ, Ying Y-S, Conrad PA, Anderson RGW: Caveolin moves from caveolae to the Golgi apparatus in response to cholesterol oxidation. $J$ Cell Biol 1994, 127:1185-1197.

195. Pelkman SL, Kartenbeck J, Helenus A: Caveolar endocytosis of simian virus 40 reveals a new two-step vesicular-transport pathway to the ER. Nat Cell Biol 2001, 3:473-483.

196. Cohen AW, Razani B, Schubert W, Williams TM, Wang XB, lyenagagr P, Brasaemle DL, Scherer PE, Lisanti MP: Role of caveolin-1 in the modulation of lipolysis and lipid droplet formation. Diabetes 2004, 53:1261-1270

197. Pol A, Luetterforst R, Lindsay M, Heino S, Ikonen E, Parton RG: A caveolin dominant negative mutant associates with lipid bodies and induces intracellular cholesterol imbalance. J Cell Biol 2001, 152:1057-1070.

198. Boström P, Andersson L, Rutberg M, Perman J, Lidberg U, Johansson BR, Fernandez-Rodriguez J, Ericson J, Nilsson T, Borén J, Olofsson SO: SNARE proteins mediate fusion between cytosolic lipid droplets and are implicated in insulin sensitivity. Nat Cell Biol 2007, 9:1286-1293.

199. Connelly MA, Kellner-Weibel G, Rothblat GH, Williams DL: SR-BI-derived HDL-cholesteryl ester hydrolysis. J Lipid Res 2003, 44:331-341.

200. Afterwood L, Hernandez HJ, Alfin-Slater RB: Effect of large doses of the oral contraceptive Enovid on cholesterol metabolism in the rat. $J$ Lipid Res 1968, 9:447-452

201. Tuckey RC, Lee G, Costa ND, Stevenson PM: The composition and distribution of lipid granules in the rat ovary. Mol Cell Endocrinol 1984, 38:187-195

202. Cheng B, Kowal J: Analysis of adrenal cholesteryl esters by reversed phase high performance chromatography. J Lipid Res 1994, 35:1115-1121.

203. Egwim PO, Kummerow FA: Influence of dietary fat on the concentration of long-chain unsaturated fatty acid families in rat tissues. J Lipid Res 1972, 13:500-10

204. Prinz WA: Non-vesicular sterol transport in cells. Prog Lipid Res 2007 46:297-314

205. Vahouny GV, Chanderbhan R, Hinds R, Hodges VA, Treadwell CR: ACTHinduced hydrolysis of cholesteryl esters in rat adrenal cells. J Lipid Res 1978, 19:570-577.

206. Azhar S, Chen Y-DI, Reaven GM: Stimulation of lipoprotein receptors and role of lipoprotein and cellular cholesterol during gonadotropininduced desensitization of steroidogenic response in luteinized rat ovary. J Biol Chem 1983, 258:3735-3740.

207. Schumacher M, Schwarz, Leidenberger F: Desensitization of mouse Leydig cells in vivo: evidence for the depletion of cellular cholesterol. Biol Reprod 1985, 33:335-345

208. Kraemer FB, Shen WJ, Natu V, Patel S, Osuga J, Ishibshi S, Azhar S: Adrenal neutral cholesteryl ester hydrolase: identification, subcellular distribution, and sex differences. Endocrinology 2002, 143:801-806.

209. Kraemer FB, Shen WJ, Harada K, Patel S, Osuga J, Ishibshi S, Azhar S: Hormone-sensitive lipase is required for high-density lipoprotein cholesteryl ester-supported adrenal steroidogenesis. Mol Endocrinol 2004, 18:549-557. 
210. Li H, Brochu M, Wang SP, Rochdi L, Cote M, Mitchell G, Gallo-payet N: Hormone-sensitive lipase deficiency in mice causes lipid storage in the adrenal cortex and impaired corticosterone response to corticotropin stimulation. Endocrinology 2002, 143:3333-3340.

211. Cook KG, Colbran RJ, Snee J, Yeaman SJ: Cytostolic cholesteryl ester hydrolase from bovine corpus luteum. Its purification, identification, and relationship to hormone-sensitive lipase. Biochim Biophys Acta 1983, 752:46-53.

212. Holm C, Belfrage P, Fredrikson G: Immunological evidence for the presence of hormone-sensitive lipase in rat tissues other than adipose tissue. Biochem Biophys Res Commun 1987, 148:99-105

213. Kraemer FB, Patel S, Saedi MS, Sztalryd C, Detection of hormone-sensitive lipase in various tissues: Expression of an HSL/bacterial fusion protein and generation of anti-HSL antibodies. J Lipid Res 1993, 34:663-6671.

214. Holst LS, Langin D, Mulder H, Laurell H, Grober J, Berg A, Mohrenweisner HW, Edgren G, Holm C: Molecular cloning, genomic organization and expression of a testicular isoform of hormone sensitive lipase. Genomics 1996, 35:441-447.

215. Yeaman SJ: Hormone-sensitive lipase-new roles for an old enzyme. Biochem J 2004, 379:11-22.

216. Kraemer FB, Patel S, Singh-Bist A, Gholami SS, Saedi MS, Sztalryd C: Detection of hormone-sensitive lipase in various tissues. II. Regulation in the rat testis by human chorionic gonadotropin. J Lipid Res 1993, 34:609-16.

217. Merry BJ: Mitochondrial structure in the rat adrenal cortex. J Anat 1975, 119:611-618.

218. Stemberger BH, Walsh RM, Patton S: Morphometric evaluation of lipid droplet associations with secretory vesicles, mitochondria and other components in the lactating cells. Cell Tissue Res 1984, 236:471-476.

219. Murphy S, Martin S, Parton RG: Lipid droplet-organelle interactions; sharing the fats. Biochim Biophys Acta 2009, 1791:441-447.

220. Zehmer JK, Huang Y, Peng G, Pu J, Anderson RG, Liu P: A role for lipid droplets in intermembrane lipid traffic. Proteomics 2009, 9:914-921.

221. Jahn R, Scheller RH: SNAREs-engines for membrane fusion. Nat Rev Mol Cell Biol 2006, 7:631-643.

222. Martens S, McMahon HT: Mechanisms of membrane fusion: disparate players and common principals. Nat Rev Mol Cell Biol 2009, 9:543-556.

223. Sühof TC, Rothman JE: Membrane fusion: grappling with SNARE and SM proteins. Science 2009, 323:474-477.

224. Jägerström MS, Polesie S, Wickström Y, Johansson BR, Schroder HD, Højlund K, Boström P: Lipid droplets interact with mitochondria using SNAP23. Cell Biol Int 2009, 33:934-940.

225. Steegmaier M, Oorschot V, Klumperman J, Scheller RH: Syntaxin 17 is abundant in steroidogenic cells and implicated in smooth endoplasmic reticulum membrane dynamics. Mol Biol Cell 2000 11:2719-2731

226. Grant NJ, Hepp R, Krause W, Aunis D, Oehme P, Langley K: Differential expression of SNAP-25 isoforms and SNAP-23 in the adrenal gland. $J$ Neurochem 1999, 72:363-372.

227. Jo M, Gieske MC, Payne CE, Wheeler-Price SE, Gieske JB, Ignatius IV, Curry $T E, K o C$ : Development and application of a rat ovarian gene expression database. Endocrinology 2004, 145:5384-5396.

228. Grosse J, Bulling A, Brucker C, Berg U, Amsterdam A, Mayerhofer A, Gratz M: Synaptosome-associated protein of 25 kilodaltons in oocytes and steroid-producing cells of rat and human ovary: molecular analysis and regulation by gonadotropins. Biol Reprod 2000, 63:643-650.

229. Shimada M, Yanai Y, Okazaki T, Yamashita Y, Sriraman V, Wilson WC, Richards JC: Snaptosomal-associated protein 25 gene expression is hormonally regulated during ovulation and is involved in cytokine/ chemokine exocytosis from granulose cells. Mol Endocrinol 2007, 21:2487-2502

230. Vahouny GH, Chanderbhan R, Noland BJ, Irwin D, Dennis P, Lambeth JD, Scallen TJ: Sterol carrier protein2. Identification of adrenal sterol carrier protein2 and site of action of mitochondrial cholesterol utilization. $J$ Biol Chem 1983, 258:11731-11737.

231. van Noort M, Rommerts FF, van Amerongen A, Wirtz KW: Intracellular redistribution of SCP2 in Leydig cells after hormonal stimulation may contribute to increased pregnenolone production. Biochem Biophys Res Commun 1988, 154:60-65.

232. Mendis-handagama SM, Aten RF, Watkins PA, Scallen TJ, Behrman HR: Peroxisomes and sterol carrier protein-2 in luteal cell steroidogenesis: a possible role in cholesterol transport from lipid droplets to mitochondria. Tissue Cell 1995, 27:483-490.

233. Seedorf U, Ellinghaus P, Roch NJ: Sterol carrier protein-2. Biochim Biophys Acta 2000, 1486:45-54.

234. Gallegos AM, Atshaves BP, Storey SM, Starodub O, Petrescu AD, Huang H, McIntosh AL, Martin GG, Chao H, Kier AB, Schroeder F: Gene structure, intracellular localization, and functional roles of sterol carrier protein2. Prog Lipid Res 2001, 40:498-563.

235. Soccio RE, Breslow JL: StAR-related lipid transfer (START) proteins: mediators of intracellular lipid metabolism. J Biol Chem 2003, 278:22183-22186.

236. Soccio RE, Adams RM, Maxwell KN, Breslow JL: Differential gene regulation of StarD4 and starD5 cholesterol transfer proteins. Activation of StarD4 by sterol regulatory element-binding protein-2 and StarD5 by endoplasmic reticulum stress. J Biol Chem 2005, 280:19410-19418.

237. Manna PR, Dyson MT, Stocco DM: Regulation of the steroidogenic acute regulatory protein gene expression: present and future perspective. Mol Hum Reprod 2009, 15:321-333.

238. Strauss JF III, Kishida T, Christenson LK, Fujimoto T, Hiroi H: START domain proteins and the intracellular trafficking of cholesterol in steroidogenic cells. Mol Cell Endocrinol 2003, 202:59-65.

239. Miller WL: StAR search-what we know about how the steroidogenic acute regulatory protein mediates mitochondrial cholesterol import. Mol Endocrinol 2007, 21:589-601.

240. Bose HS, Whittal RM, Ran Y, Bose M, Baker BY, Miller WL: StAR-like activity and molten globule behavior of StARD6, a male germ-line protein. Biochemistry 2008, 47:2277-2288

241. Rodriguez-Agudo D, Ren S, Hylemon PB, Redford K, Natarajan R, Del Castillo A, Gil G, Pandak WM: Human StarD5, a cytostolic STAR-related lipid binding protein. J Lipid Res 2005, 46:1615-1623.

242. Rodriguez-Agudo D, Ren S, Wong E, Marques D, Redford K, Gil G, Hylemon P, Pandak WM: Intracellular transporter StarD4 binds free cholesterol and increases cholesteryl ester formation. J Lipid Res 2008, 49:1409-1419.

243. Sewer MB, Li D: Regulation of steroid hormone biosynthesis by the cytoskeleton. Lipids 2008, 43:1109-1115

244. Hall PF: The roles of microfilaments and intermediate filaments in the regulation of steroid synthesis. J Steroid Biochem Mol Biol 1995 55:601-605

245. Fuchs E, Weber K: Intermediate filaments: structure, dynamics, function, and disease. Annu Rev Biochem 1994, 63:345-382.

246. Czernobilsky B, Moll R, Levy R, Franke WW: Co-expression of cytokeratin and vimentin filaments in mesothelial, granulosa and rete ovarii cells of the human ovary. Eur J Cell Biol 1985, 37:175-190.

247. Ortega HH, Lorente JA, Salvetti NR: Immunohistochemical study of intermediate filaments and neuroendocrine marker expression in Leydig cells of laboratory rodents. Anat Histol Embryol 2004, 33:309-315.

248. Almahbobi G, Williams LJ, Hall PF: Attachment of mitochondria to intermediate filaments in adrenal cells: relevance to the regulation of steroid synthesis. Exp Cell Res 1992, 200:361-369.

249. Almahbobi G, Williams LJ, Hall PF: Attachment of steroidogenic lipid droplets to intermediate filaments in adrenal cells. J Cell Sci 1992, 101:389-393

250. Almahbobi G, Williams LJ, Han XG, Hall PF: Binding of lipid droplets and mitochondria to intermediate filament in rat Leydig cells. J Reprod Fertil 1993, 98:1209-1217

251. Wu CC, Howell KE, Neville MC, Yates JR, McManaman JL: Proteomics reveal a link between the endoplasmic reticulum and lipid secretory mechanisms in mammary epithelial cells. Electrophoresis 2000, 21:3470-3482

252. Brasaemle DL, Dolios G, Shapiro L, Wang R: Proteomic analysis of proteins associated with lipid droplets of basal and lipolyticallystimulated 3T3-L1 adipocytes. J Biol Chem 2004, 279:46835-46842.

253. Bartz R, Zehmer JK, Zhu M, Chen Y, Serrero G, Zhao Y, Liu P: Dynamic activity of lipid droplets: protein phosphorylation and GTP-mediated protein translocation. J Proteome Res 2007, 6:3256-3265.

254. Wang C, JeBailey L, Ridgway ND: Oxysterol-binding protein (OSBP)related protein 4 binds 25 -hydroxycholesterol and interacts with vimentin intermediate filaments. Biochem J 2002, 361:461-472. 
255. Wyles JP, Perry RJ, Ridgway ND: Characterization of the sterol-binding domain of oxysterol-binding protein (OSBP)-related protein 4 reveals a novel in vimentin organization. Exp Cell Res 2007, 313:1426-1437.

256. Chou YH, Flitney FW, Chang L, Mendez M, Grin B, Goldman RD: The motility and dynamic properties of intermediate filaments and their constituent proteins. Exp Cell Res 2007, 313:2236-2243.

257. Kumar N, Robidoux J, Daniel KW, Guzman G, Floering LM, Collins S: Requirement of vimentin filament assembly for $\beta_{3}$-adrenergic receptor activation of ERK MAP kinase and lipolysis. J Biol Chem 2007, 282:9244-9250.

258. Holwell TA, Schweitzer SC, Reyland ME, Evans RM: Vimentin-dependent utilization of LDL-cholesterol in human adrenal tumor cells is not associated with the level of expression of apoE, sterol carrier protein-2, or caveolin. J Lipid Res 1999, 40:1440-1452.

259. Collot M, Louvard D, Singer SJ: Lysosomes are associated with microtubules and not with intermediate filaments in cultured filaments in cultured fibroblasts. Proc Natl Acad Sci USA 1984, 81:788-792

260. Thomson M: Molecular and cellular mechanisms used in the acute phase stimulated steroidogenesis. Horm Metab Res 1998, 30:16-28.

261. Ferguson JJ Jr: Protein synthesis and adrenocorticotropin responsiveness. J Biol Chem 1963, 238:2754-2759.

262. Cooke BA, Janszen FH, Clotscher WF, van der Molen HJ: Effect of proteinsynthesis inhibitors on testosterone production in rat testis interstitial tissues and Leydig-cell preparation. Biochem J 1975, 150:413-418.

263. Azhar S, Menon M, Menon KMJ: Receptor-mediated gonadotropin action in the ovary. Demonstration of acute dependence of rat luteal cells on exogenously supplied steroid precursor (sterols) for gonadotropin-induced steroidogenesis. Biochim Biophys Acta 1981, 665:362-375.

264. Stocco DM: Intramitochondrial cholesterol transfer. Biochim Biophys Acta 2000, 1486:184-197.

265. Kruger RJ, Orme-Johnson NR: Acute adrenocorticotropic hormone stimulation of adrenal cortosteroidogenesis. Discovery of a rapidly induced protein. J Biol Chem 1983, 258:10159-10167.

266. Pon LA, Orme-Johnson NR: Acute stimulation of steroidogenesis in corpus luteum and adrenal cortex by peptide hormones. Rapid induction of a similar protein in both tissues. J Biol Chem 1986, 261:6594-6599.

267. Pon LA, Hartigan JA, Orme-Johnson NR: Acute ACTH regulation of adrenal corticosteroid biosynthesis. Rapid accumulation of a phosphoprotein. J Biol Chem 1986, 261:13309-13316.

268. Alberta JA, Epstein LF, Pon LA, Orme-Johnson NR: Mitochondrial localization of a phosphoprotein that rapidly accumulates in adrenal cortex cells exposed to adrenocorticotropic hormone or to cAMP. $J$ Biol Chem 1989, 264:2368-2372.

269. Epstein LF, Orme-Johnson NR: Regulation of steroid hormone biosynthesis. Identification of precursors of a phosphoprotein targeted to the mitochondria in stimulated rat adrenal cortex cells. $J$ Biol Chem 1991, 266:19739-19745.

270. Pon LA, Epstein LF, Orme-Johnson NR: Acute cAMP stimulation in Leydig cells: rapid accumulation of a phosphoprotein similar to that detected in adrenal cortex and corpus luteum. Endocr Res 1986, 12:429-446.

271. Pon LA, Orme-Johnson NR: Acute stimulation of corpus luteum cells by gonadotrophin or adenosine 3',5'-monophosphate causes accumulation of a phosphoprotein concurrent with acceleration of steroid synthesis. Endocrinology 1988, 123:1942-1948.

272. Epstein LF, Orme-Johnson NR: Acute action of luteinizing hormone on mouse Leydig cells: accumulation of mitochondrial phosphoproteins and stimulation of testosterone synthesis. Mol Cell Endocrinol 1991, 81:113-126.

273. Stocco DM, Sodeman TC: The 30-kDa mitochondrial protein is induced by hormone stimulation in MA-10 mouse Leydig tumor cells are processed from larger precursors. J Biol Chem 1991, 266:19731-19738.

274. Clark BJ, Wells J, King SR, Stocco DM: The purification, cloning, and expression of a novel luteinizing hormone-induced mitochondrial protein in MA-10 mouse Leydig tumor cells. Characterization of the steroidogenic acute regulatory protein (StAR). J Biol Chem 1994, 269:28314-28322

275. Bauer MP, Bridgbam JT, Langenau DM, Johnson AL, Goetz FW: Conservation of steroidogenic acute regulatory (StAR) protein structure and expression in vertebrates. Mol Cell Endocrinol 2000, 168:119-125.

276. Lin D, Sugawara T, Strauss JF, Clark BJ, Stocco DM, Saenger P, Rogol A, Miller WL: Role of steroidogenic acute regulatory protein in adrenal and gonadal steroidogenesis. Science 1995, 267:1828-1831.

277. Sugawara T, Holt JA, Driscoll D, Strauss JF, Lin D, Miller WL, Patterson D, Clancy KP, Hart IM, Clark BJ, Stocco DM: Human steroidogenic acute regulatory protein (StAR): Functional activity in COS-1 cells, tissue specific expression, and mapping of the structural gene to $8 p 11.2$ and an expressed pseudogene to chromosome 13. Proc Natl Acad Sci USA 1995, 92:4778-4782.

278. Tee MK, Lin D, Sugawara T, Holt JA, Guiguen Y, Buckingham B, Strauss JF, Miller WL: T T A transconversion $11 \mathrm{bp}$ from a splice acceptor site in the gene for steroidogenic acute regulatory protein causes congenital lipoid adrenal hyperplasia. Hum Mol Genet 1995, 4:2299-2305.

279. Caron KM, Soo S-C, Wetsel WC, Stocco DM, Clark BJ, Parker KL: Targeted disruption of the mouse gene encoding steroidogenic acute regulatory protein provides insights into congenital lipoid adrenal hyperplasia. Proc Natl Acad Sci USA 1997, 94:1150-11545.

280. Hasegawa T, Zhao L, Caron KM, Majdic G, Suzuki T, Shizawa S, Sasano H, Parker KL: Developmental roles of the steroidogenic acute regulatory protein (StAR) as revealed by StAR knockout mice. Mol Endocrinol 2000, 14:1462-1471

281. Pollack SE, Furth EE, Kallen CB, et al: Localization of acute regulatory protein in human tissues. J Clin Endocrinol Metab 1997, 82:4243-4251.

282. Kallen CB, Billheimer JT, Summers SA, Stayrook SE, Lewis M, Strauss JF: Steroidogenic acute regulatory protein (StAR) is a sterol transfer protein. J Biol Chem 1998, 273:26285-26288.

283. Petrescu AD, Gallegos AM, Ckamura Y, Strauss JF III, Schroeder F: Steroidogenic acute regulatory protein binds cholesterol and modulates membrane sterol domain dynamics. J Biol Chem 2001, 276:36970-36982

284. Wang X, Liu Z, Eimeryl S, Timberg R, Weiss AM, Orly J, Stocco DM: Effect of truncated forms of the steroidogenic acute regulatory protein on intramitochondrial cholesterol transfer. Endocrinology 1998, 139:3903-3912.

285. Arakane F, Kallen CB, Watri H, Foster JA, Sepuri NB, pain D, Stayrook SE, Lewis M, Greton GL, Strauss JF: The mechanism of action of steroidogenic acute regulatory protein (StAR): StAR acts on the outside of mitochondria to stimulate steroidogenesis. J Biol Chem 1998, 373:16339-16345

286. Bose HS, Lingappa VR, Miller WL: Rapid regulation of steroidogenesis by mitochondrial protein import. Nature 2002, 417:87-91.

287. Baker BY, Yaworsky DC, Miller WL: A pH-dependent molten globule transition is required for activity of the steroidogenic acute regulatory protein, StAR. J Biol Chem 2005, 280:41753-41760.

288. Rone MB, Fan J, Papadopoulos V: Cholesterol transport in steroid biosynthesia: Role of protein-protein interactions in disease states. Biochim Biophys Acta 2009, 1791:646-658.

289. Stocco DM: StAR protein and the regulation of steroid hormone biosynthesis. Annu Rev Physio/ 2001, 63:193-213.

290. Krueger KE, Papadopoulos V: Mitochondrial benzodiazepine receptors and the regulation of steroid biosynthesis. Annu Rev Pharmacol Toxicol 1992, 32:211-237.

291. Papadopoulos V: Peripheral-type benzodiazepine/diazepam binding inhibitor receptor: biological role in steroidogenic cell function. Endocr Rev 1993, 14:222-240.

292. Papadopoulos V, Baraldi M, Guilarte TR, Knudsen TB, Lacapère J J, Lindemann P, Norenberg MD, Nutt D, Weizman A, Zhnag MR, Gavish M: Translocator protein $(18 \mathrm{kDa})$ : new nomenclature for the peripheraltype benzodiazepine receptor-based on its structure and molecular function. Trends Pharmacol Sci 2006, 27:402-409.

293. Gavish M, Bachman R, Shoukrun Y, Katz Y, Veenman L, Weisinger G, Weizman A: Enigma of the peripheral benzodiazepine receptor. Pharmacol Rev 1999, 51:629-650.

294. Mukhin AG, Papodopoulos V, Costa E, Kruger KE: Mitochondrial benzodiazepine receptors regulate steroid biosynthesis. Proc Nat/ Acad Sci USA 1989, 86:9813-9816.

295. Yanagibashi K, Ohno Y, Nakamichi N, Matsui T, Hayashida K, Takamura M, Yamada K, Tou S, Kawamura M: Peripheral-type benzodiazepine receptors are involved in the regulation of cholesterol side-chain 
cleavage in adrenal mitochondria. J Biochem (Tokyo) 1989, 106:1026-1029.

296. Papadopoulos V, Mukhin AG, Costa E, Krueger KE: The peripheral-type benzodiazepine receptor is functionally linked to Leydig cell steroidogenesis. J Biol Chem 1990, 265:3772-3779.

297. Krueger KE, Papadopoulos V: Peripheral-type benzodiazepine receptors mediate translocation of cholesterol from outer to inner mitochondrial membranes in adrenocortical cells. J Biol Chem 1990, 265:15015-15022.

298. Papadopoulos V, Nowzari FB, Krueger KE: Hormone-stimulated steroidogenesis is coupled to mitochondrial benzodiazepine receptors. Tropic hormone action on steroid biosynthesis is inhibited by flunitrazepam. J Biol Chem 1991, 266:3682-3687.

299. Li H, Yao Z, Degenhardt B, Teper G, Papadopoulos V: Cholesterol binding at the cholesterol recognition interaction amino acid consensus (CRAC) of the peripheral-type benzodiazepine receptor and inhibition of steroidogenesis by an HIV TAT-CRAC peptide. Proc Natl Acad Sci USA 2001, 98:1267-1272.

300. Jamin N, Neumann JM, Ostuni MA, Vu TK, Yao ZX, Murail S, Robert JC, Giatzakis C, Papadopoulos V, Lacapère JJ: Characterization of the cholesterol recognition amino acid consensus sequence of the peripheral benzodiazepine receptor. Mol Endocrinol 2005, 19:588-594

301. Papadopoulos V, Amir H, Li H, Boujard N, Vidic B, Gamier VM: Targeted disruption of the peripheral-type benzodiazepine receptor gene inhibits steroidogenesis in the R2C Leydig tumor cell line. J Biol Chem 1997, 272:32129-32135

302. West LA, Horvat RD, Roess DA, Barisas BG, Juengel JL, Niswender GD: Steroidogenic acute regulatory protein (StAR) and peripheral-type benzodiazepine receptor associate at the mitochondrial membrane. Endocrinology 2001, 142:502-505.

303. Bogan RL, Davis TL, Niswender GD: Peripheral-type benzodiazepine receptor (PBR) aggregation and absence of steroidogenic acute regulatory protein (StAR)/PBR association in the mitochondrial membrane as determined by bioluminescence resonance energy transfer (BRET). J Steroid Biochem Mol Biol 2007, 104:61-67.

304. Hauet T, Yao ZX, Bose HS, Wall CT, Han Z, Li W, Hales DB, Miller WL, Culty M, Papadopoulos V: Peripheral-type benzodiazepine receptormediated action of steroidogenic acute regulatory protein on cholesterol entry into Leydig cell mitochondria. Mol Endocrinol 2005, 19:540-554

305. [http://commons.wikimedia.org/wiki/File:steroidogenesis.svg].

306. Farese RV Jr, Walther TC: Lipid droplets finally get a little R-E-S-P-E-C-T. Cell 2009, 139:855-860.

doi: $10.1186 / 1743-7075-7-47$

Cite this article as: Hu et al., Cellular cholesterol delivery, intracellular processing and utilization for biosynthesis of steroid hormones Nutrition \& Metabolism 2010, 7:47

\section{Submit your next manuscript to BioMed Centra} and take full advantage of:

- Convenient online submission

- Thorough peer review

- No space constraints or color figure charges

- Immediate publication on acceptance

- Inclusion in PubMed, CAS, Scopus and Google Scholar

- Research which is freely available for redistribution

Submit your manuscript at www.biomedcentral.com/submit
C BioMed Central 